\title{
ARTICLE
}

Received 15 Sep 2014 | Accepted 15 Dec 2014 | Published 20 Jan $2015 \quad$ DOl: 10.1038/ncomms7100

\section{Vaginal type-II mucosa is an inductive site for primary CD8 + T-cell mucosal immunity}

Yichuan Wang ${ }^{1}$, Yongjun Sui ${ }^{1}$, Shingo Kato ${ }^{1}$, Alison E. Hogg ${ }^{1,2}$, Jason C. Stee ${ }^{3,4}$, John C. Morris ${ }^{5} \&$ Jay A. Berzofsky ${ }^{1}$

The structured lymphoid tissues are considered the only inductive sites where primary T-cell immune responses occur. The naïve Tcells in structured lymphoid tissues, once being primed by antigen-bearing dendritic cells, differentiate into memory $T$ cells and traffic back to the mucosal sites through the bloodstream. Contrary to this belief, here we show that the vaginal type-II mucosa itself, despite the lack of structured lymphoid tissues, can act as an inductive site during primary $\mathrm{CD} 8^{+} \mathrm{T}$-cell immune responses. We provide evidence that the vaginal mucosa supports both the local immune priming of naïve $\mathrm{CD} 8^{+} \mathrm{T}$ cells and the local expansion of antigen-specific CD8 ${ }^{+}$T cells, thereby demonstrating a different paradigm for primary mucosal T-cell immune induction.

\footnotetext{
${ }^{1}$ Vaccine Branch, Center for Cancer Research, National Cancer Institute, National Institute of Health, Bethesda, Maryland 20892, USA. ${ }^{2}$ Aeras, 1405 Research Boulevard, Rockville, Maryland 20850, USA. ${ }^{3}$ The University of Queensland, Brisbane, Queensland 4120, Australia. ${ }^{4}$ Gallipoli Medical Research Foundation, Greenslopes, Queensland 4120, Australia. ${ }^{5}$ University of Cincinnati Cancer Institute, Cincinnati, Ohio 45267, USA. Correspondence and requests for materials should be addressed to Y.S. (email: Suiy@mail.nih.gov) or to J.A.B. (email: berzofsj@mail.nih.gov).
} 
ying at the interface between host and environment, the mucosal tissue acts as the port of entry for multiple pathogens. During viral transmission through mucosal tissues, the presence of local antigen (Ag)-specific immune cells is considered to help control infections by multiple viruses, such as influenza virus $(\mathrm{Flu})^{1-3}$, human immunodeficiency virus $(\mathrm{HIV})^{4-8}$, Simian immunodeficiency virus $(\mathrm{SIV})^{9-11}$ and herpes simplex virus (HSV) ${ }^{12-15}$. Although the mucosal local Ag-specific $\mathrm{T}$ cells play an important role to protect against viral transmission, the mechanisms through which the local Agspecific T-cell immunity can be generated in mucosal tissues, especially in type-II mucosa (found in vagina, glans penis and oesophagus) ${ }^{16-19}$, remain to be elucidated.

It is widely believed that primary immune T-cell induction in type-II mucosa occurs only in the draining lymph nodes (DLNs) but not in the mucosa itself due to a lack of mucosa-associated lymphoid tissue (MALT) or secondary lymphoid tissues ${ }^{16-19}$. In this process, the naïve $\mathrm{T}$ cells in DLNs are primed by the Agbearing dendritic cells (DCs) migrating from the Ag-exposed mucosa and differentiate into memory $\mathrm{T}$ cells that are then able to traffic back to mucosal sites through the bloodstream ${ }^{20-23}$. It has been shown that local secondary immune responses can protect against viral infection ${ }^{24-26}$, and that protective vaginal immunity can occur in lymph node-deficient mice $^{13}$, as well as that lymphoid clusters can form in virus-infected vaginal mucosa ${ }^{15}$. However, whether a primary immune response can be induced locally in the type-II mucosal tissues without help from any distant tissue or lymphoid site remains a fundamental question to be answered.

In the current study, we develop a unique dual-transfer model, by which we clearly demonstrate that adoptively transferred naïve OT-I CD8 ${ }^{+} \mathrm{T}$ cells are activated in the vaginal mucosa but not in the DLNs $24 \mathrm{~h}$ after intravaginally (Ivag) immunization under conditions where cells from the circulation or DLNs cannot reach the vaginal mucosa. Even without adoptive transfer, Ag-specific $\mathrm{CD}^{+}{ }^{+} \mathrm{T}$-cell activation is found to occur locally in the vaginal mucosa after vaginal immunization before it occurs in DLNs. In addition, the immunized vaginal tissue can induce naïve OT-I $\mathrm{CD}^{+}$T-cell activation that is largely dependent on local antigen-presenting cells (APCs). Finally, vaginal mucosa also supports the local expansion of Ag-specific CD8 ${ }^{+} \mathrm{T}$ cells. In conclusion, we present an evidence of a new paradigm for primary CD8 ${ }^{+}$T-cell immune induction in type-II mucosa of the vagina, one that occurs locally without the help of draining LNs, MALT or any other tissue site of priming, thereby providing a new rationale for local mucosal immunization.

\section{Results}

DLN-independent priming of $\mathrm{CD8}^{+} \mathrm{T}$ cells in vaginal mucosa. Our study started with our observation that Ivag-immunized LNdeficient lymphotoxin-alpha-knockout (LT $\alpha$ KO) mice ${ }^{27,28}$ could still be immunized Ivag despite lack of DLNs. To test the necessity of DLNs for vaginal CD8 ${ }^{+}$T-cell immune induction, we used a replication-deficient adenovirus-5-expressing the hen ovalbumin immunodominant $\mathrm{K}^{\mathrm{b}}$-restricted SIINFEKL peptide (rAd5SIINFEKL) to Ivag immunize the LN-deficient lymphotoxinalpha-knockout (LT $\alpha \mathrm{KO}$ ) mice ${ }^{27,28}$ (Fig. 1a) and measured the vaginal SIINFEKL-specific $\mathrm{CD}^{+} \mathrm{T}$ cells 14 days post immunization (PI). Significantly elevated levels of SIINFEKLspecific $\mathrm{CD}^{+}{ }^{+} \mathrm{T}$ cells could be detected in the vaginal mucosa of LT $\alpha$ KO mice (Fig. 1b,c), although the percentage was lower than that in wild-type (WT) animals. To understand the vaginal T-cell distribution after Ivag immunization, we examined the vaginal tissue sections and found that immunization-induced $\mathrm{CD}^{+}{ }^{+}$cell clusters formed in both WT and LT $\alpha$ KO mice (Fig. 1d). To further identify the phenotype of cluster-forming cells, we stained CD8 and CD11c on the consecutively cut tissue sections right next to each other. The adjacent tissue section staining showed that the $\mathrm{CD}^{+}$cell clusters in the immunized mice also contained $\mathrm{CD}^{+}$and $\mathrm{CD}^{+} \mathrm{c}^{+}$cells (Fig. 1d). In contrast to the immunized mice, the vaginal $\mathrm{CD}^{+}{ }^{+}$cells in naïve animals did not form clusters, but rather they were present sporadically as isolated cells in lamina propria (LP) and epithelium (Fig. 1d). These results clearly demonstrated that primary Ivag immunization could induce the LN-independent Ag-specific $\mathrm{CD}^{+}{ }^{+}$-cell immune response associated with the immune cell aggregation, that is, the formation of inducible vaginal lymphoid tissue (IVALT). Although the IVALT-associated Agspecific $\mathrm{CD}^{+}$T-cell response can be induced in the vaginal mucosa independent of LNs, consistent with the recent findings on protective immunity of Roth et al. ${ }^{13}$, we still do not know whether these Ag-specific $\mathrm{CD}^{+}{ }^{+} \mathrm{T}$ cells are derived from the primed local naive $\mathrm{T}$ cells in the vaginal mucosa or they migrate from other non-lymphoid tissue compartments, such as the liver ${ }^{29-31}$. To test whether or not the vaginal mucosa itself could act as an inductive site for the primary $\mathrm{CD} 8^{+}{ }^{+}$-cell immune responses, we wanted to determine whether a primary $\mathrm{CD} 8{ }^{+}$ $\mathrm{T}$-cell response could be generated locally in the vaginal mucosa of WT mice.

The availability of naïve $\mathrm{CD8}^{+} \mathrm{T}$ cells in vaginal mucosa. Because the availability of naïve $\mathrm{T}$ cells is a prerequisite for the generation of primary $\mathrm{T}$-cell immune responses, we first assessed whether naïve $\mathrm{CD} 8{ }^{+} \mathrm{T}$ cells were present in the vaginal mucosa. To ensure the $\mathrm{CD}^{+}{ }^{+} \mathrm{T}$ cells we identified from the digested vaginal tissue were the interstitial cells, we intravenously (i.v.) injected fluorochrome-labelled Thy1.2 antibody at a dose of $25 \mathrm{ng}$ per mouse that could stain all the $\mathrm{T}$ cells in the blood collected from retro-orbital plexus within 1 min (Supplementary Fig. 1a), which means that all the vasculature $T$ cells can be stained by this method. Using the intravascular T-cell staining ${ }^{32}$, we can clearly distinguish the interstitial $\mathrm{T}$ cells from the blood $\mathrm{T}$ cells, although some of the tissue-residing cells might be stained by the antibody that leaks out from the capillaries, so the unstained cells represent a lower limit on the number of tissue-residing cells. In digested vaginal tissues, we found that around $86 \%$ (median $=86.7 \%$ ) of naïve $\mathrm{CD}^{+} \mathrm{T}$ cells (CD62 $\mathrm{L}^{\text {high }} / \mathrm{CD} 44^{\text {low }}$ ) were present extravascularly, that is, in the vaginal mucosal parenchyma, but not in associated vasculature (Supplementary Fig. 1a,b).

We then examined the phenotype of vaginal $\mathrm{CD}^{+} \mathrm{T}$ cells from mice treated either with or without FTY720, a sphingosine1-phosphate receptor agonist, which inhibits lymphocyte egress from both thymus and lymph nodes ${ }^{33}$ (Fig. 2). In FTY720untreated mice, $44 \%(44.7 \% \pm 4.1 \%$; mean \pm s.e.m. $)$ of vaginal $\mathrm{CD}^{+} \mathrm{T}$ cells showed a naïve phenotype characterized as $\mathrm{CD}_{62} \mathrm{~L}^{+}, \mathrm{CD} 44^{\text {low }}$ and lacking CD25 and CD69 expression (Fig. 2b,c). Four days after FTY720 treatment, the naïve CD8 ${ }^{+}$ T-cell population in the vaginal mucosa was lost (Fig. 2b,c).

To determine the location of $\mathrm{CD} 8{ }^{+} \mathrm{T}$ cells in vaginal mucosa, we assayed the number of vaginal CD8 $\beta^{+}$cells in the mice either with or without FTY720 treatment by immunohistochemistry (IHC; Fig. 2d,e). In FTY720-treated animals, the ratio of LP $\mathrm{CD} 8 \beta^{+}$cells/intraepithelial (IEP) $\mathrm{CD} 8 \beta^{+}$cells significantly decreased $(P<0.0001$ by a Student's $t$-test $)$ from $2.03 \pm 0.097$ (mean \pm s.e.m.) to $0.53 \pm 0.059$ (Fig. $2 \mathrm{~d}$,e). Although it is difficult to count and compare the absolute number of total $\mathrm{CD} 8{ }^{+} \mathrm{T}$ cell in both LP and IEP due to the sporadic cell distribution, the lower LP/IEP ratio in FTY720-treated animals is highly suggestive of FTY720-induced vaginal naïve T-cell depletion occurring to a greater extent in the LP. Even though naïve lymphocytes are 
a

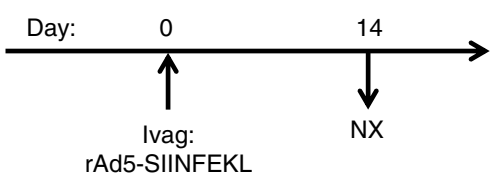

C

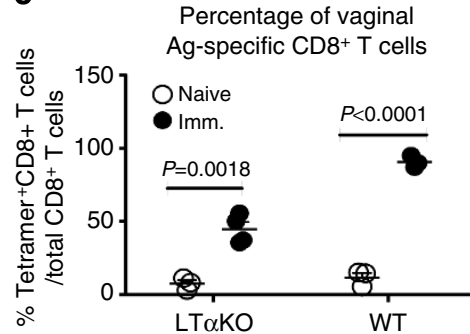

b

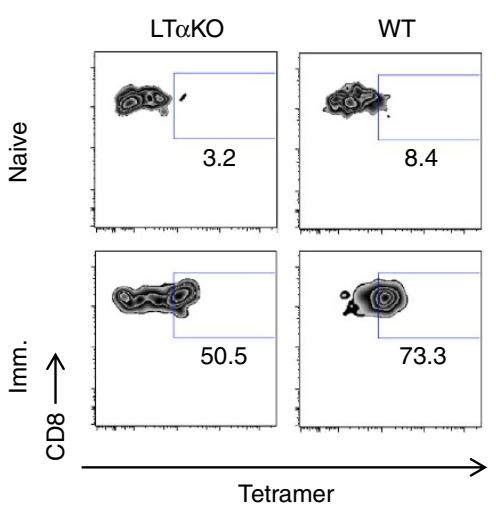

d
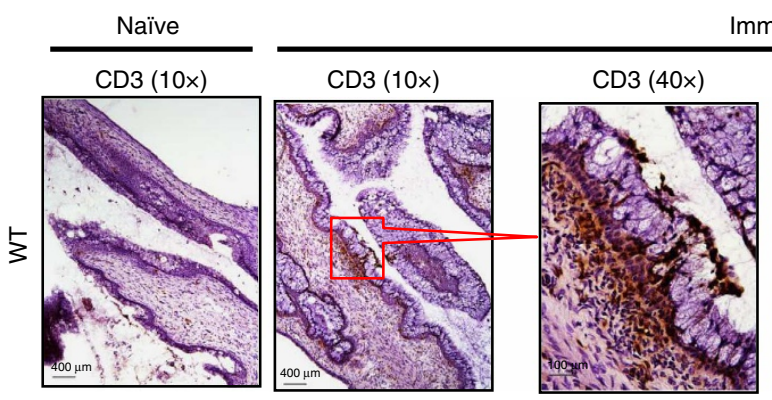

Imm
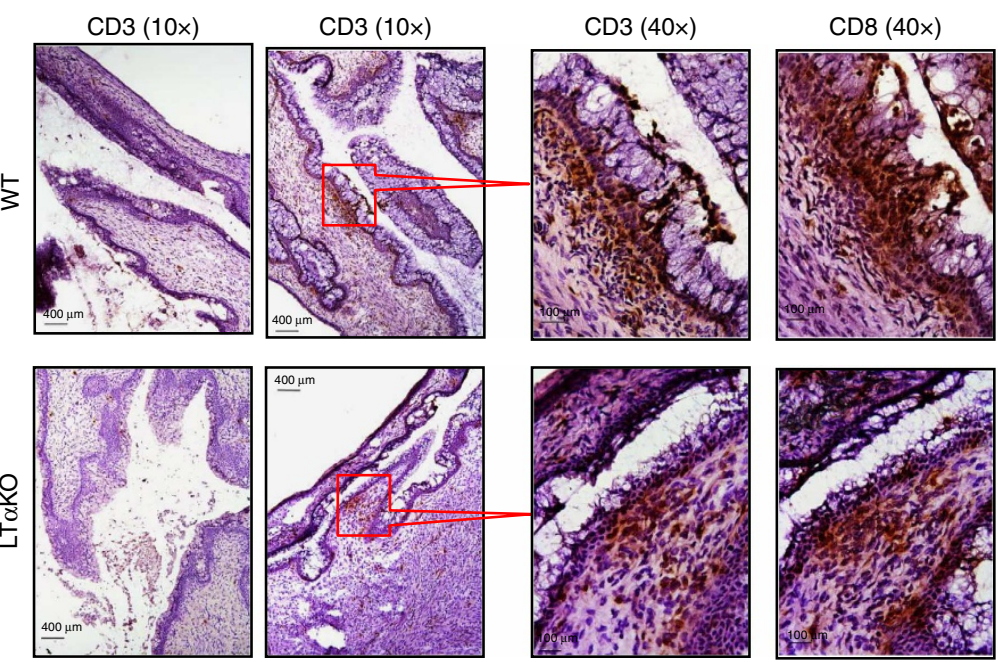

$\operatorname{CD} 11 \mathrm{c}(40 \mathrm{x})$
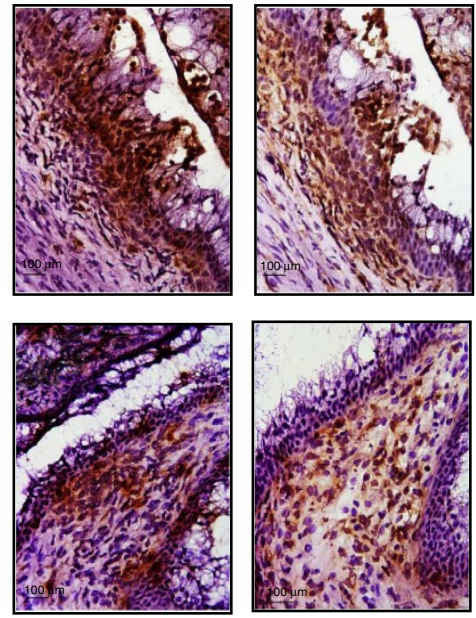

Figure 1 | Vaginal Ag-specific CD8 ${ }^{+}$T-cell immune responses in LT $\alpha$ KO LN-deficient mice. (a-c) The percentage of SIINFEKL-specific CD8 ${ }^{+}$T cells in the vaginal mucosa of both $L T \alpha K O, L N$-deficient mice and WT mice. This is representative of two independently repeated experiments $(n=3$ per naïve control group; $n=4$ per immunized group) with the same results. (a) Experimental design. (b) The gating strategy. (c) The percentage (mean \pm s.e.m.) of SIINFEKL-specific vaginal CD8 ${ }^{+}$T cells in each group. The $P$ value was generated using Student's $t$-test. (d) Representative IHC staining showing the formation of immune cell clusters containing $\mathrm{CD}^{+}{ }^{+} \mathrm{CD}^{+}$and $\mathrm{CD}_{11 c^{+}}$cells in the immunized WT and LT $\alpha \mathrm{KO}$ mice. Scale bar: $100 \mu \mathrm{m}$ in $\times 40$ photomicrographs; $400 \mu \mathrm{m}$ in $\times 10$ photomicrographs. Imm, immunized.

known to preferentially recirculate among the secondary lymphoid organs ${ }^{34,35}$, there is an increasing evidence showing that $\mathrm{CD}^{+}{ }^{+}$recent thymic emigrants migrate directly into the small intestine and that naïve $\mathrm{T}$ and $\mathrm{B}$ lymphocytes are present in multiple peripheral tissue compartments ${ }^{36-39}$. Therefore, our data demonstrated that naïve $\mathrm{CD} 8{ }^{+} \mathrm{T}$ cells routinely migrated into the vaginal mucosal LP and the maintenance of this population depended on the lymphocyte recirculation or replenishment from the bloodstream.

Naïve T-cell vaginal mucosal priming $24 \mathrm{~h}$ post Ivag vaccine. To determine whether the naive $\mathrm{CD} 8{ }^{+} \mathrm{T}$ cells could be primed locally in the vaginal mucosa of WT mice, independent of DLNs, we developed a dual-transfer model (Fig. 3a). We isolated CD8 ${ }^{+}$ T cells from Rag1 KO, OT-I transgenic C57BL/6 mice that solely express a T-cell receptor (TCR) recognizing the ovalbumin peptide SIINFEKL-H-2K $\mathrm{K}^{\mathrm{b}}$ complex. We depleted CD $44^{\text {high }}$ cells from the OT-I CD8 ${ }^{+} \mathrm{T}$ cells to enrich the naïve population (CD44 ${ }^{\text {low }}$ and $\mathrm{CD}^{2} \mathrm{~L}^{+}$) to $98.5 \%$ (Fig. 3a). Identical aliquots of the naïve OT-I CD8 ${ }^{+}$T cells were labelled with either carboxyfluorescein succinimidyl ester (CFSE; green) or violet dye and adoptively transferred either Ivag or i.v., respectively, into the same recipient mouse that had been Ivag immunized either $8 \mathrm{~h}$ (Fig. $3 \mathrm{~b}$ ) or $32 \mathrm{~h}$ (Fig. 4a) earlier with SIINFEKL peptide plus DOTAP, a cationic liposome facilitating major histocompatibility complex-I-restricted Ag presentation, and mutant labile toxin (mLT), a mucosal adjuvant. To further block lymphocyte recirculation, we also gave each mouse FTY720 at $24 \mathrm{~h}$ before euthanasia, which decreased the number of blood $\mathrm{CD}^{+} \mathrm{T}$ cells to background levels from 8-24h post treatment (Fig. 3a).

To validate the reliability of our dual-transfer system, we tested the effectiveness of $\mathrm{T}$-cell recirculation blockage mediated by FTY720 treatment. WT mice received FTY720 IP injection followed by i.v.-transferred, CFSE-labelled naïve $\mathrm{CD}^{+}{ }^{+} \mathrm{T}$ cells $\left(5 \times 10^{6}\right.$ per mouse $)$ at $8 \mathrm{~h}$ after FTY720 treatment. Sixteen hours after adoptive transfer, we collected and combined five vaginal tissues from the mice that had received either naïve $\mathrm{CD} 8{ }^{+} \mathrm{T}$ cells 
a
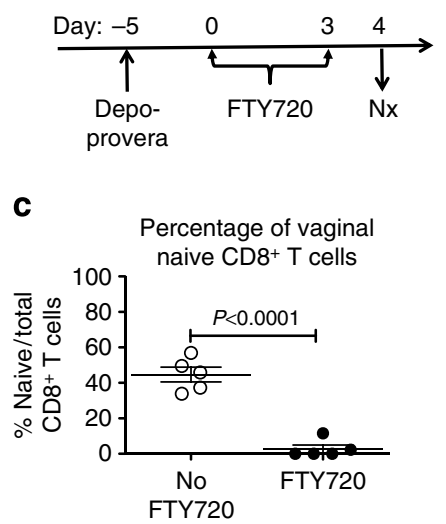

d

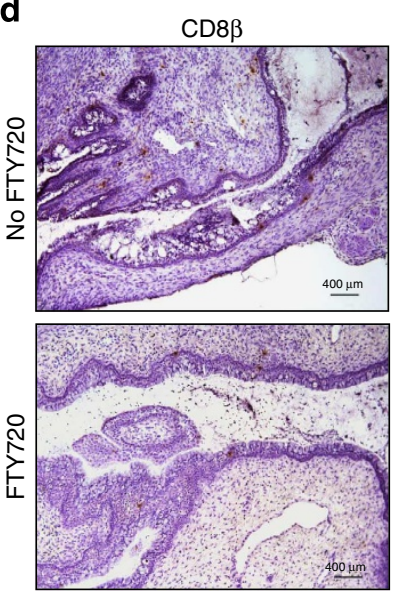

b

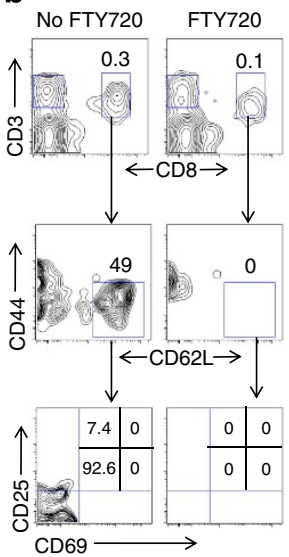

e

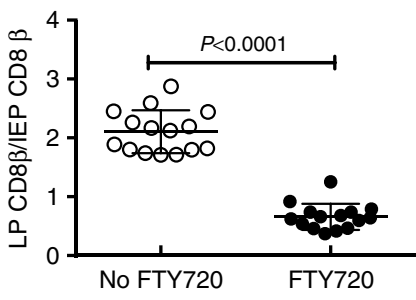

Figure 2 | The phenotype and distribution of $\mathrm{CDB}^{+} \mathbf{T}$ cells in vaginal mucosa of WT mice with or without FTY720 treatment. (a-c) The naïve $\mathrm{CD}^{+}{ }^{+} \mathrm{T}$ cells in the vaginal mucosa of WT mice with depo-proverasynchronized oestrous cycle. This is representative of three independently repeated experiments $(n=5)$ with the same results. (a) Experimental design. (b) The gating strategy to identify vaginal naïve CD8 ${ }^{+} \mathrm{T}$ cells. (c) The percentage (mean \pm s.e.m.) of naïve $\mathrm{CD} 8{ }^{+} \mathrm{T}$ cells in vaginal mucosa with or without FTY720 treatment. (d,e) Representative results of vaginal IHC staining showing the distribution of $C 8 \beta^{+}$cells in vaginal LP and epithelium. (d) Representative IHC photomicrographs showing the CD8 $\beta^{+}$cell in both vaginal epithelium and LP of the mice treated either with or without FTY720 (Scale bar, $400 \mu \mathrm{m}$ ). (e) The ratio of LP C $8 \beta^{+}$ cells/IEP C $8 \beta^{+}$cells summarized from the pool of three independently repeated experiments $(n=15)$. The numbers of LP and IEP C $8 \beta^{+}$cells were counted from three vaginal tissue sections from each animal. To avoid counting the same cell multiple times on adjacent tissue sections, we selected the slides with the vaginal tissue sections that were cut $25 \mu \mathrm{m}$ apart based on the diameter of T cells $(5-20 \mu \mathrm{m})$ (ref. 63). The $P$ value was generated using a Student's t-test.

or naïve $\mathrm{CD} 8{ }^{+} \mathrm{T}$ cells plus FTY720 or PBS. The transferred naïve $\mathrm{CD}^{+} \mathrm{T}$ cells were examined using flow cytometry and no $\mathrm{CFSE}^{+}$events were noted in the vaginal tissues from the FTY720-treated mice, whereas they were clearly detected in the absence of FTY720. This is direct evidence that FTY720 completely blocked the naive $\mathrm{CD} 8{ }^{+} \mathrm{T}$-cell vaginal infiltration from the blood stream (Supplementary Fig. 2).

We investigated the vaginal $\mathrm{CD} 8{ }^{+} \mathrm{T}$-cell immune priming at $24 \mathrm{~h}$ PI (16 h after dual transfer; Fig. 3b). In the vaginal mucosa, the only detectable transferred population was the green CFSElabelled cell population injected directly into the vaginal mucosa
(Fig. 3c). The percentage of green CFSE-labelled OT-I CD8 ${ }^{+}$ $\mathrm{T}$ cells out of total vaginal $\mathrm{CD}^{+} \mathrm{T}$ cells was about $50 \%$ $(51.2 \% \pm 4.9 \%$; mean \pm s.e.m. $)$, which means the number of transferred naïve $\mathrm{CD}^{+} \mathrm{T}$ cells within the vaginal tissue was similar to that of the endogenous $\mathrm{CD}^{+} \mathrm{T}$ cells (that is, physiological levels; Fig. 3c). The CD69 expression of Ivagtransferred cells was significantly higher in the Ivag-immunized mice $(84 \% \pm 2.9 \%$; mean \pm s.e.m. $)$ than the naïve control animals $(10.9 \% \pm 2.7 \%$; mean \pm s.e.m.; $P<0.0001$ by a Student's $t$-test; Fig. $3 \mathrm{c}, \mathrm{e})$, indicating that these cells were primed by the Ivag immunization. Since the violet-labelled i.v.-transferred cells were not detectable in the vaginal mucosa $24 \mathrm{~h}$ after immunization (Fig. 3c), there were no transferred $\mathrm{T}$ cells entering the vaginal mucosa through the bloodstream in the presence of FTY720. Therefore, the green $\mathrm{CD} 69^{+}$Ivag-transferred cells would not yet have been able to traffic back to vaginal mucosa from the DLNs (or any other tissue) where they could potentially have been activated. Thus, the $\mathrm{CD}^{+} 9^{+}$green Ivag-transferred cells in the vaginal mucosa had to be primed locally. For comparison, the draining iliac LN contained both i.v.-transferred and Ivagtransferred cells (Fig. 3d). The i.v.-transferred cells showed similar low levels of CD69 expression in the immunized as in the naive animals, indicating a lack of priming in the DLN by the Ivag immunization at $24 \mathrm{~h}$. In contrast, the CD69 expression of the green Ivag-transferred cells was significantly higher in the immunized mice than unimmunized mice. Since the violetlabelled i.v.-transferred cells had not been activated in the iliac LN by $24 \mathrm{~h} \mathrm{PI}$, those green $\mathrm{CD} 69^{+}$Ivag-transferred cells in iliac LNs would not have been activated in the LNs, but should be the ones activated in the vaginal mucosa that then migrated into the DLNs.

For further confirmation, we also performed a similar dualtransfer study in LN-deficient lymphotoxin-alpha-knockout (LT $\alpha$ KO) mice 27,28 (Fig. 3f-h). Similar to what was observed in WT mice, the green Ivag-transferred cells within the vaginal mucosa were activated at $24 \mathrm{~h}$ PI without any evidence of any T-cell vaginal homing through the bloodstream (violet i.v.-transferred cells; Fig. 3f,h). Because the LT $\alpha$ KO mice don't develop any LNs, we checked the liver that also possesses multiple immune functions ${ }^{29}$. Similar to what has been shown by other groups ${ }^{30,31}$, the immune priming, characterized by the expression of CD69 on i.v.-transferred violet cells, was detected in the liver that contained only the i.v.-transferred violet cells, but not the Ivag-transferred green cells (Fig. 3g,h). Even though the naïve $\mathrm{CD}^{+} \mathrm{T}$ cells were able to be activated in the liver, none of the liver-primed (violet) $\mathrm{CD}^{+} \mathrm{T}$ cells could enter the vaginal mucosa (Fig. 3f,h). Direct priming in the vaginal mucosa was further confirmed in a second LN-deficient mouse model, CXCR5 $\mathrm{KO}$ mice ${ }^{40}$, in which the Ivag-transferred green cells could be primed locally in vaginal mucosa, while no violet cells from the blood had entered the mucosa (Supplementary Fig. 3). Thus, the data from both WT and LN-deficient mice clearly demonstrated that the Ivag-transferred naive $\mathrm{CD}^{+} \mathrm{T}$ cells could be primed locally in this type-II mucosa, without any signs of LN immune priming and/or the trafficking of $\mathrm{CD} 8{ }^{+} \mathrm{T}$ cells through the blood from any other tissue site to the vaginal mucosa. Therefore, we conclude that the naïve CD ${ }^{+} \mathrm{T}$ cells could be primed locally in the vaginal mucosa independent of LNs, contrary to the wellaccepted paradigm.

Naïve T-cell vaginal mucosal priming $48 \mathrm{~h}$ post Ivag vaccine. To characterize the kinetics of immune priming in vaginal mucosa and in draining LNs, we extended our observations to $48 \mathrm{~h}$ PI (Fig. 4a). In the vaginal mucosa, still containing no violet i.v.-transferred cells, the green Ivag-transferred cells still remained activated, although at a lower level than observed at $24 \mathrm{~h}$ PI 
a

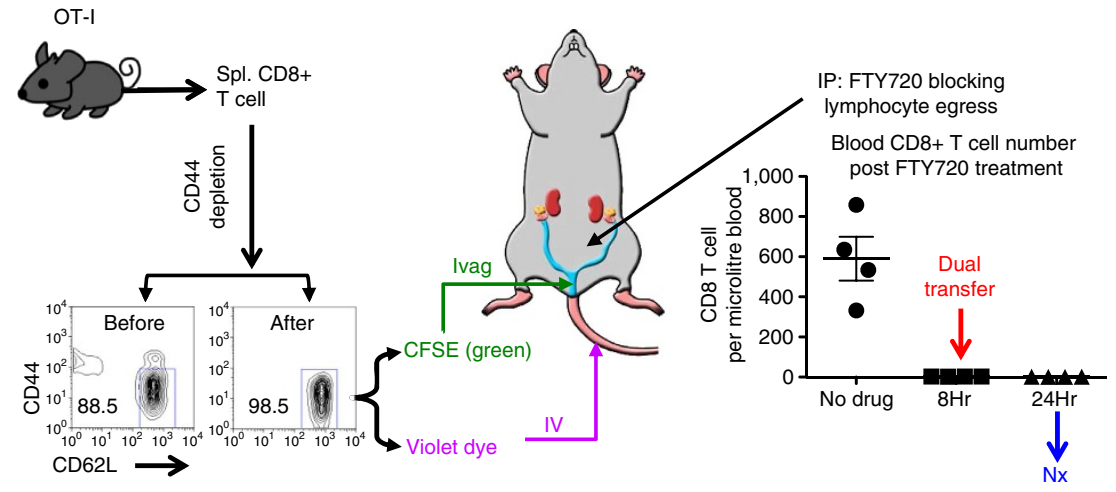

b IP: FTY720

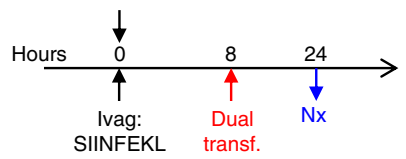

d

C
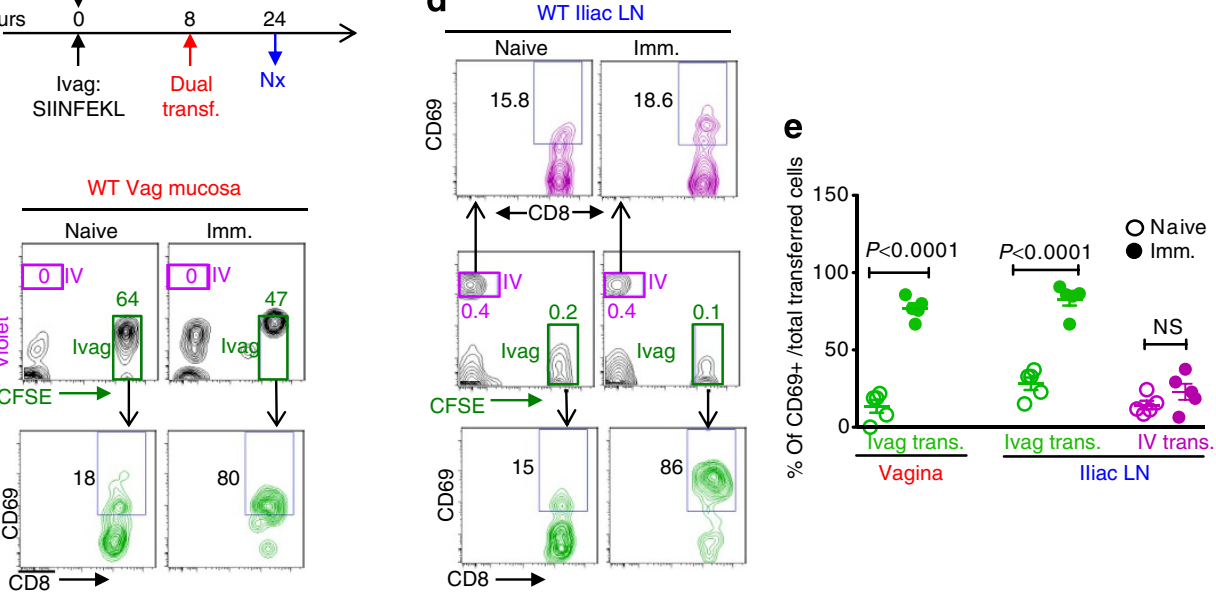

$\mathbf{f}$

LT $\alpha$ KO vag mucosa
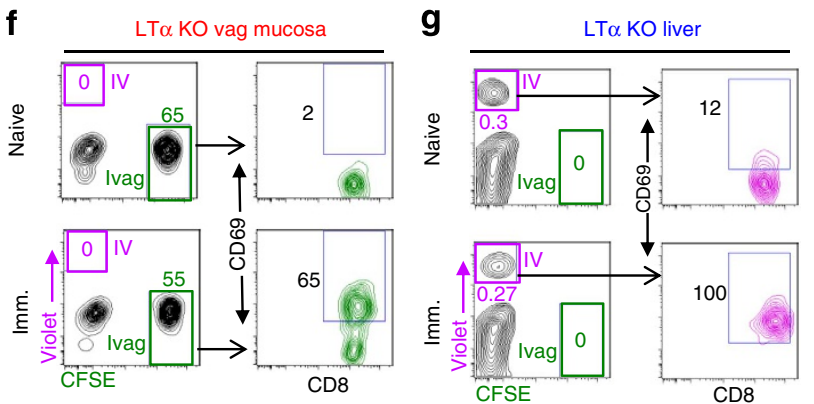

h

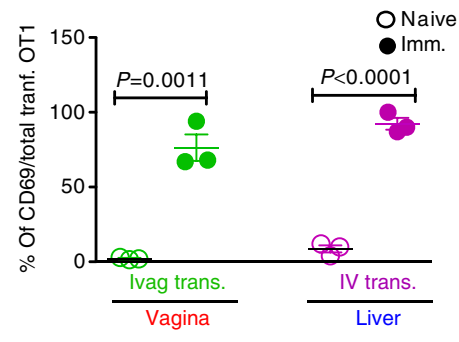

Figure 3 | The CD69 expression of Ivag- versus i.v.-transferred naïve OT-I CD8 ${ }^{+}$T cells in WT and LN-deficient LT $\alpha$ KO mice at $24 \mathrm{~h}$ PI. (a) The dualtransfer model. (b)The experimental design. (c-e) The CD69 expression of transferred naïve OT-I CD8 ${ }^{+}$T cells in the vaginal mucosa and iliac LNs of WT mice. This is representative of three independently repeated experiments ( $n=5$ for WT animals; $n=3$ for LT $\alpha$ KO animals) with the same results. (c) The total and CD69-expressing transferred naïve OT-I CD8 ${ }^{+}$T cell in the vaginal mucosa. (d) The total and CD69-expressing transferred naïve OT-I CD8 ${ }^{+}$ T cell in the iliac LNs. (e) The percentage (mean \pm s.e.m.) of CD69 expression in each group. (f-h) The total and CD69-expressing transferred naïve OT-I CD8 ${ }^{+}$T cells in the vaginal mucosa and the liver of LN-deficient LT $\alpha$ KO mice. This is representative of two independently repeated experiments with the same results. (f) The total and CD69-expressing transferred naïve OT-I CD8 ${ }^{+}$T cell in vaginal mucosa of LT $\alpha$ KO mice. (g) The total and CD69expressing transferred naïve OT-I CD8 ${ }^{+}$T cell in liver of LT $\alpha$ KO mice. (h) The percentage (mean \pm s.e.m.) of CD69 expression in each group. The $P$ value was generated using a Student's t-test. Imm., immunized.

(Fig. 4b,d). In the iliac LN, the violet i.v.-transferred cells started being activated by $48 \mathrm{~h}$, as assessed by the high level of CD69 in the immunized compared with unimmunized mice (Fig. 4c,d). The ability to detect priming of violet i.v.-transferred cells in the DLN at $48 \mathrm{~h}$ may be due to the migration of vaginal Ag-bearing DCs to the draining LNs by $48 \mathrm{~h}$. Therefore, the Ag-specific immune activation of naive $\mathrm{CD} 8{ }^{+} \mathrm{T}$ cells could take place in both vaginal mucosa and DLNs at $48 \mathrm{~h}$ PI, but also at this time point, priming in the DLN could not account for primed T cells in the vaginal mucosa in the presence of FTY720, as no i.v.-transferred cells were yet able to enter the vaginal mucosa (Fig. 4b).

Naïve vaginal T-cell priming under physiological conditions. The dual-transfer study clearly demonstrated that the immune priming of naïve vaginal $\mathrm{CD} 8{ }^{+} \mathrm{T}$ cells could be a completely local process (Figs 3 and 4). We further confirmed whether local 
a

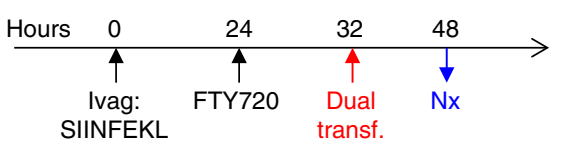

b

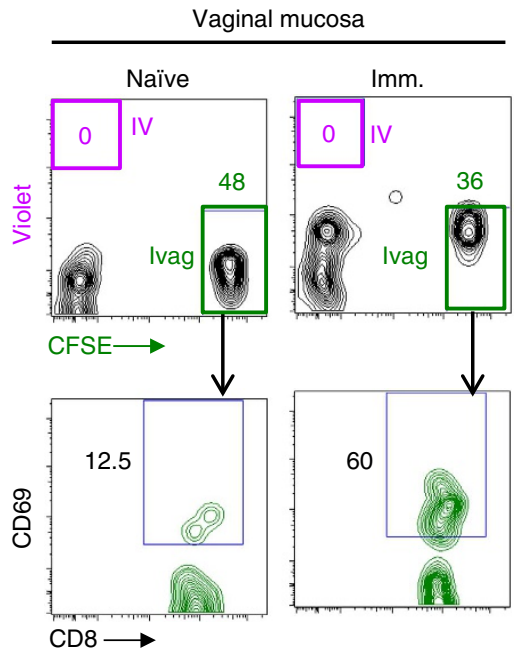

C

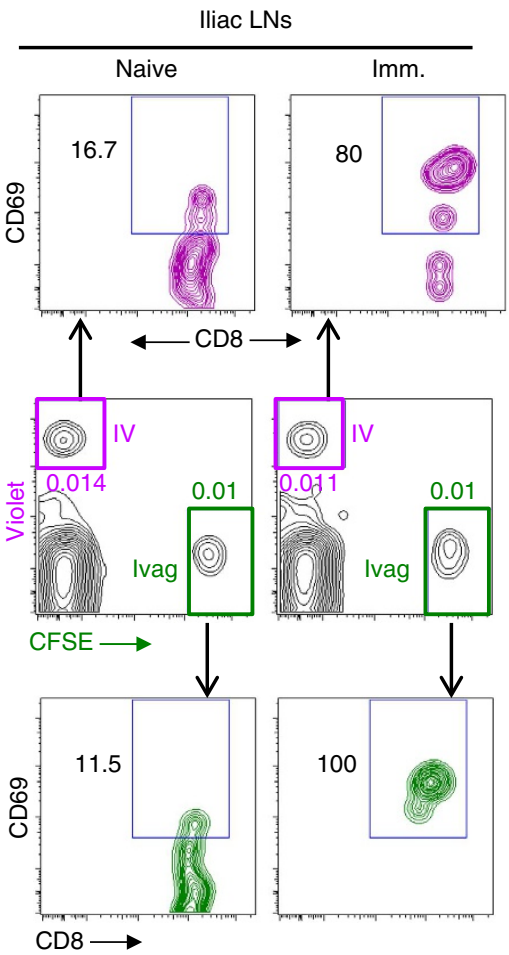

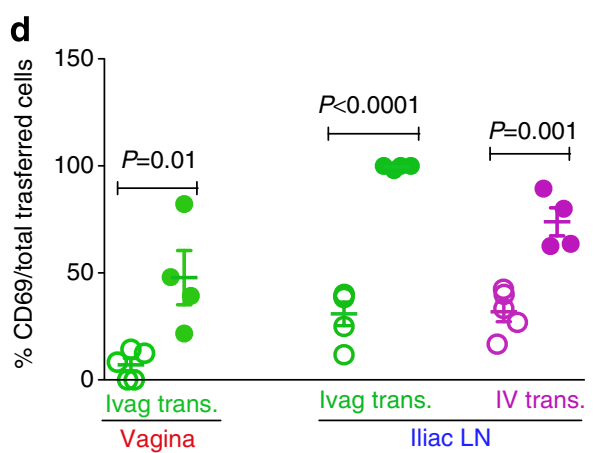

Figure 4 | The CD69 expression of Ivag- versus i.v.-transferred OT-I CD8 ${ }^{+} \mathbf{T}$ cells in vaginal mucosa and iliac LNs at $48 \mathbf{~}$ PI. (a) The experimental design. (b) The total and CD69-expressing transferred OT-I CD8 ${ }^{+}$T cells in vaginal mucosa. (c) The total and CD69-expressing transferred OT-I CD8 ${ }^{+}$ T cells in iliac LNs. (d) The percentage (mean \pm s.e.m.) of CD69+ OT-I CD8 ${ }^{+}$T cells in each group. This is representative of two independently repeated experiments ( $n=5$ per naïve group; $n=4$ per immunized group) with the same results. $P$ value was generated using a Student's $t$-test. Imm., immunized.

immune priming could occur in completely intact vaginal mucosa without adoptive transfer of the T cells. We studied the Ag-specific immune activation of vaginal $\mathrm{CD}^{+} \mathrm{T}$ cells in Ivag-immunized Rag-I KO, OT-I transgenic mice (Fig. 5). At $8 \mathrm{~h}$ after immunization, the CD69 expression of $\mathrm{CD}^{+} \mathrm{T}$ cells could be detected only in vaginal mucosa but not in DLNs (iliac LNs) (Fig. 5a,b) or in any other tissue compartments including axillary LNs, inguinal LNs, spleen and lung (Supplementary Fig. 4). Thus, the CD69-expressing CD8 ${ }^{+} \mathrm{T}$ cells detected at $8 \mathrm{~h}$ after immunization provided supportive evidence that immune priming is likely to be a local process occurring in the vaginal mucosa but not in the DLNs. In contrast, only at $12 \mathrm{~h}$ after immunization, priming was starting to occur in the DLNs (Fig. 5a,b). Thus, the kinetics support our conclusion from the dual-transfer studies (Figs 3 and 4) that priming can occur directly in the vaginal mucosa without requiring migration of cells primed in the DLN. Also, we see again that priming in the DLN occurs later than in the mucosa. To further confirm that the CD69-expressing CD8 ${ }^{+}$
T cells originated from the phenotypically naïve cells $\left(\mathrm{CD} 62 \mathrm{~L}^{+}\right.$ and $\mathrm{CD} 44^{\mathrm{low}}$ population) that were the majority $(86.5 \% \pm 2.4 \%$; mean \pm s.e.m.) of total vaginal $\mathrm{CD}^{+} \mathrm{T}$ cells in unimmunized OT-I mice (Fig. 5c, left plots and Fig. 5d), we checked the CD62L and CD44 expression on the CD69-expressing CD8 ${ }^{+} \mathrm{T}$ cells in the vaginal mucosa of both naïve and immunized animals (Fig. $5 \mathrm{c}$ right plots and Fig. 5e). In the immunized animals at $8 \mathrm{~h} \mathrm{PI}$, the percentage of naïve cells among total vaginal $\mathrm{CD} 8^{+} \mathrm{T}$ cells dropped down to $62.1 \% \pm 1.2 \%$ (mean \pm s.e.m.), which was significantly lower ( $P=0.0009$ by a Student's $t$-test) than that of unimmunized animals (Fig. 5c, left plots and Fig. 5d). More importantly, among the subset that expressed the CD69 activation marker, the percentage of CD $44^{\text {low }}$ and CD62 $\mathrm{L}^{+}$cells out of the total CD69-expressing $\mathrm{CD}^{+} \mathrm{T}$ cells was $50.6 \% \pm 1.4 \%$ (mean \pm s.e.m.), which was significantly higher $(P=0.0012$ by a Student's $t$-test) than that of naive animals $(5.3 \% \pm 5.3 \%$; mean \pm s.e.m.; Fig. $5 \mathrm{c}$ right plots and Fig. 5e). Therefore, the CD69 was expressed mostly by the vaginal CD8 ${ }^{+} \mathrm{T}$ cells with the 
a

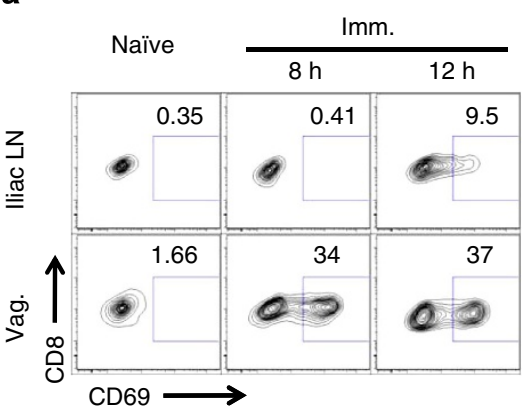

b

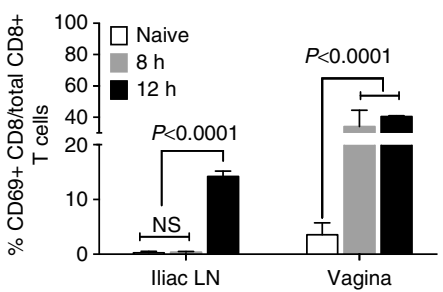

c

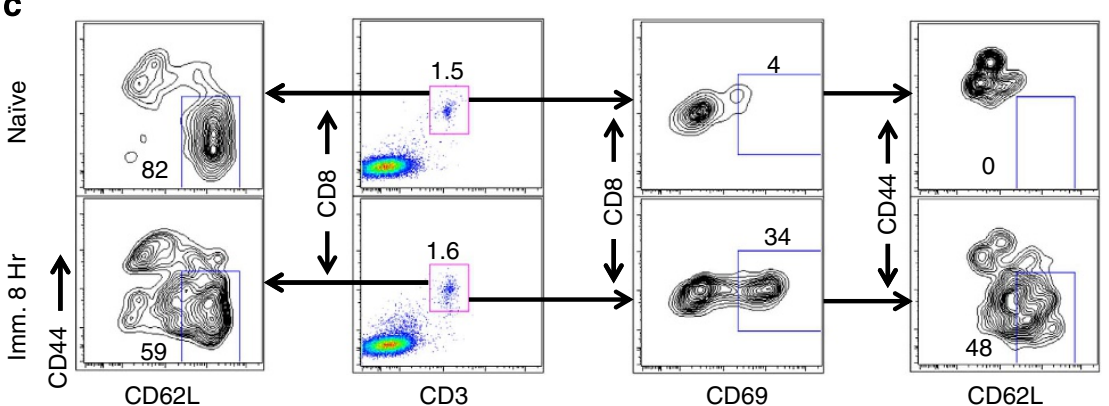

d

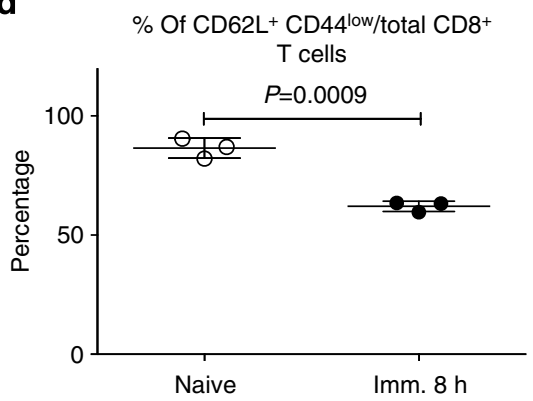

e $\%$ Of CD62L + CD44 low/total CD69+ $\mathrm{CD} 8^{+}$

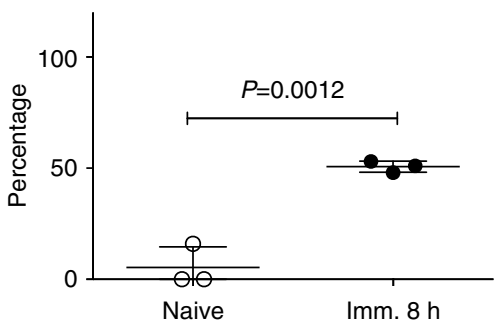

Figure 5 | The local immune priming of endogenous CD8 ${ }^{+} \mathbf{T}$ cells that naturally migrate into the physiologically intact vaginal mucosa. The phenotype of endogenous vaginal CD8 ${ }^{+}$T cells in the Ivag SIINFEKL-immunized RAG-I KO, OT-I transgenic mice. This is representative of two independently repeated experiments $(n=3)$ with the same results. $(\mathbf{a}, \mathbf{b})$ The CD69 expression of CD8 ${ }^{+}$T cells in vaginal mucosa and iliac LNs of naïve and immunized animals, which were killed at 8 and $12 \mathrm{~h} \mathrm{Pl}$. (a) Gating strategy. (b) The statistical difference (mean \pm s.e.m.) among the naïve and the two immunized groups. The $P$ value was generated using a one-way analysis of variance plus Tukey's multiple comparison. (c) The gating strategies for the phenotype assay of vaginal $\mathrm{CD}^{+} \mathrm{T}$ cells in naïve and immunized animals at $8 \mathrm{~h}$ after immunization. Left plots, the percentage of CD62 $\mathrm{L}^{+}$and $\mathrm{CD} 44^{\text {low }}$ cells out of total vaginal $\mathrm{CD}^{+}{ }^{+} \mathrm{T}$ cells. Middle left plots, the percentage of vaginal CD8 ${ }^{+} \mathrm{T}$ cells. Middle right plots, the percentage of CD69-expressing cells out of total vaginal $\mathrm{CD} 8{ }^{+} \mathrm{T}$ cells. Right plots, the percentage of $\mathrm{CD} 62 \mathrm{~L}^{+} \mathrm{CD} 44^{\text {low }}$ cells out of total CD69-expressing vaginal $\mathrm{CD} 8^{+} \mathrm{T}$ cells. (d) The statistical difference (mean \pm s.e.m.) of $\mathbf{c}$, left plots. (e) The statistical difference (mean \pm s.e.m.) of c, right plots. The $P$ values were generated using Student's $t$-test. Imm., immunized.

naive phenotype $\left(\mathrm{CD} 62 \mathrm{~L}^{+}\right.$and $\left.\mathrm{CD} 44^{\text {low }}\right)$ that had not yet downregulated CD62L or upregulated CD44 at $8 \mathrm{~h}$ after immunization, but not $\mathrm{CD} 8{ }^{+} \mathrm{T}$ cells with the memory phenotype $\left(\mathrm{CD} 62 \mathrm{~L}^{-}\right.$and $\left.\mathrm{CD} 44^{\text {high }}\right)$. This shows that the primed cells are derived from the naïve population and not the tiny fraction of memory cells in the unimmunized mucosa. Taken together, this experiment confirmed that the local immune priming can occur on the naïve endogenous $\mathrm{CD}^{+} \mathrm{T}$ cells that naturally migrate into the physiologically intact vaginal mucosa before any priming occurs in the DLN.

DC-dependent activation of naïve $\mathbf{T}$ cells in vaginal tissue. To completely isolate vaginal mucosa from all the other tissue compartments, we developed a vaginal tissue culture system (Fig. 6a). To detect the presence in the vaginal mucosa of APCs that had taken up Ag after Ivag immunization and could prime naïve T cells, we Ivag immunized mice with SIINFEKL peptide and resected the vaginal tissue at day 1 PI (Fig. 6a). The vaginal tissue was digested in medium containing collagenase and DNase followed by CD8 depletion to remove any endogenous CD8 ${ }^{+} \mathrm{T}$ cells primed either within the vaginal mucosa or in the DLNs followed by vaginal homing (Fig. 6a). We co-cultured the CD8depleted vaginal tissue together with CFSE-labelled naïve OT-I $\mathrm{CD}^{+} \mathrm{T}$ cells for 4 days without adding any Ag to the culture (Fig. 6a) and tested Ag-specific $\mathrm{CD}^{+}{ }^{+} \mathrm{T}$-cell proliferation by measuring CFSE dilution of the $\mathrm{T}$ cells cultured with the immunized vaginal tissue compared with those cultured with unimmunized vaginal tissue. Being co-cultured with the immunized vaginal tissue, naïve OT-I CD8 ${ }^{+} \mathrm{T}$ cells underwent substantial proliferation as compared with those co-cultured with tissue from unimmunized mice (Fig. 6b,c). Moreover, if CD11c ${ }^{+}$ cells (including DCs) were depleted from the immunized vaginal tissue, the proliferation of OT-I CD8 ${ }^{+} \mathrm{T}$ cells was largely lost 


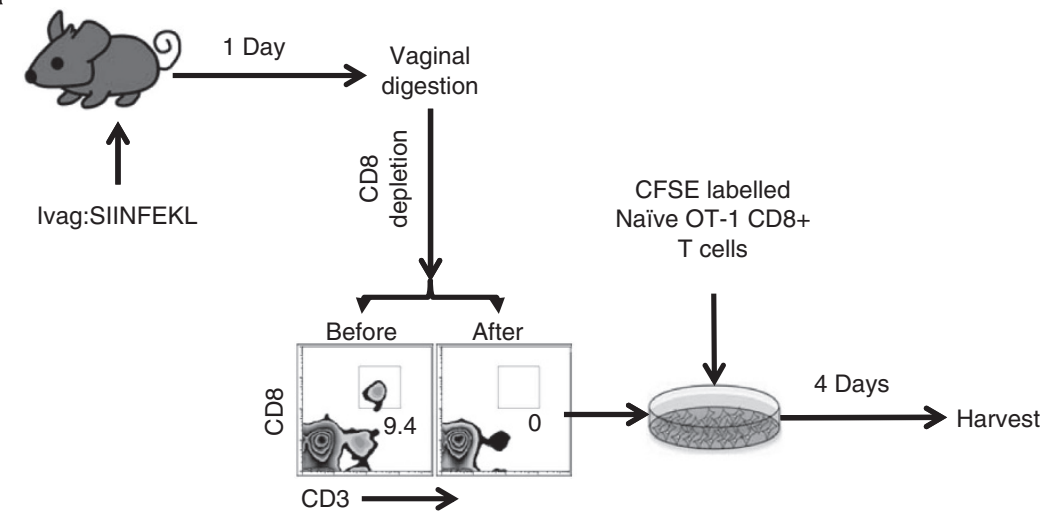

b

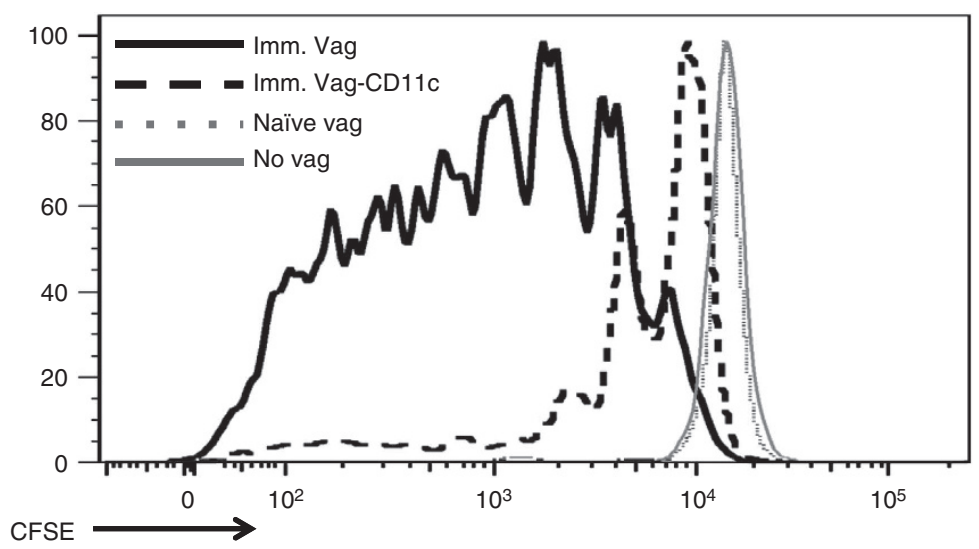

C

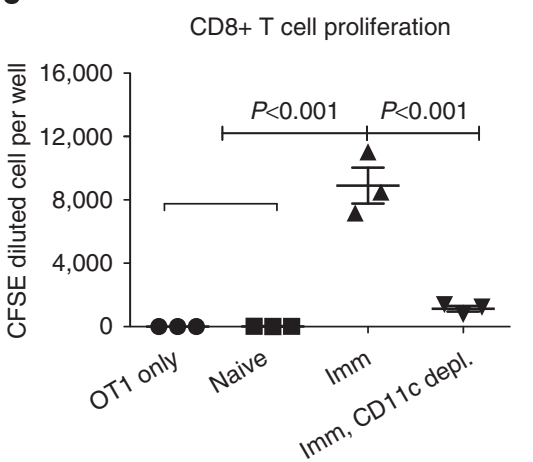

d

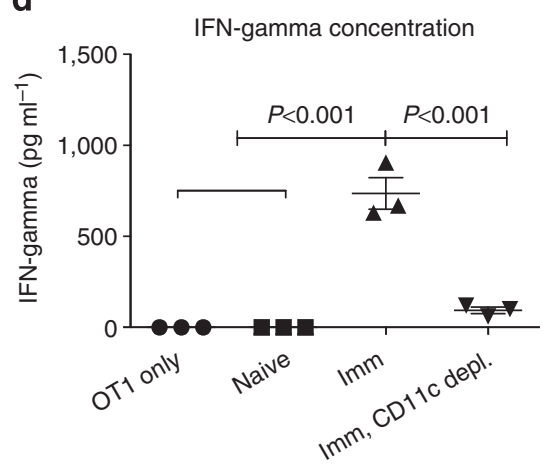

Figure 6 | The naïve OT-I CD8 ${ }^{+} \mathbf{T}$ cells activated in surgically resected vaginal tissue. (a) The experimental design. (b) The CFSE dilution of naïve OT-I CD8 ${ }^{+}$T cells in each culture. (c) The absolute number (mean \pm s.e.m.) of CFSElow cells in each culture. (d) The IFN- $\gamma$ concentration (mean \pm s.e.m.) in the supernatant of each culture. This is representative of two independently repeated experiments $(n=3$ per group of culture containing the pool of three digested vaginal tissues) with the same results. $P$ values were generated using a one-way analysis of variance plus Tukey's multiple comparison. Imm., immunized.

(Fig. 6b,c). Similarly, the cultures containing both immunized vaginal tissue and naïve OT-I CD8 ${ }^{+} \mathrm{T}$ cells showed significantly higher levels of IFN- $\gamma$ that was also dependent on the presence of $\mathrm{CD}_{11 \mathrm{c}^{+}}$cells that had taken up Ag during Ivag immunization (Fig. 6d). Therefore, the activation of naïve CD8 ${ }^{+} \mathrm{T}$ cells in the vaginal tissue required local vaginal APCs that were able to take up $\mathrm{Ag}$ at the time of Ivag immunization and then present it later to naïve $\mathrm{CD} 8{ }^{+} \mathrm{T}$ cells locally in the vaginal mucosa, without the benefit of LNs (not present in these vaginal tissue preparations).

Local expansion of Ag-specific CD8 $\mathrm{T}$ cells in vaginal mucosa. We also asked whether the vaginal mucosa could support the local expansion of Ag-specific $\mathrm{CD}^{+} \mathrm{T}$ cells. We characterized the kinetics of $\mathrm{CD} 8{ }^{+} \mathrm{T}$-cell immune responses by measuring the tetramer-positive $\mathrm{CD} 8{ }^{+} \mathrm{T}$ cells at different time points after Ivag immunization with rAd5-gp140 (Supplementary Fig. 5a). Day 7 was the earliest time point at which we could detect Ag-specific $\mathrm{CD}^{+} \mathrm{T}$ cells in both the vaginal mucosa and the draining iliac LNs (Supplementary Fig. 5b). We therefore decided to block T-cell egress from LNs by FTY720 treatment starting from day 5 PI (Fig. 7a). The FTY720 treatment decreased blood Ag-specific $\mathrm{CD}^{+} \mathrm{T}$ cells to a background level, similar to that in either naïve animals or the immunized animals sacrificed at day 5 PI (Fig. 7b). In contrast, a similar amount of Ag-specific CD8 ${ }^{+} \mathrm{T}$ cells were found in vaginal mucosa of FTY720-treated as untreated 
a

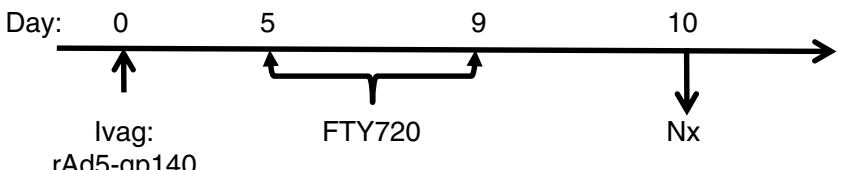

b

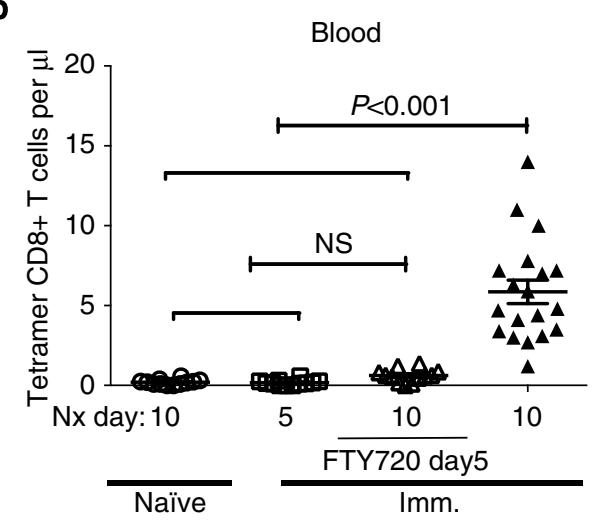

d
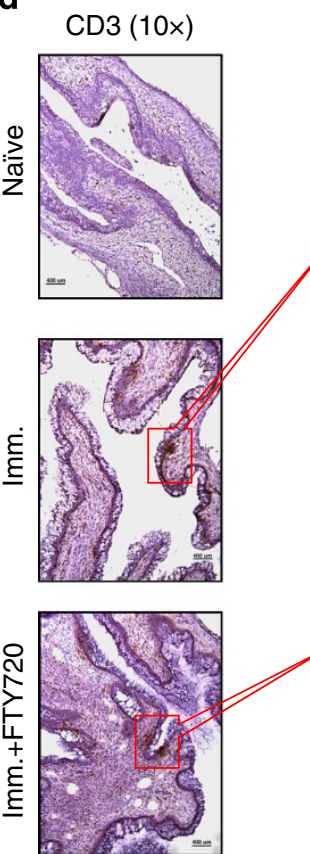

C
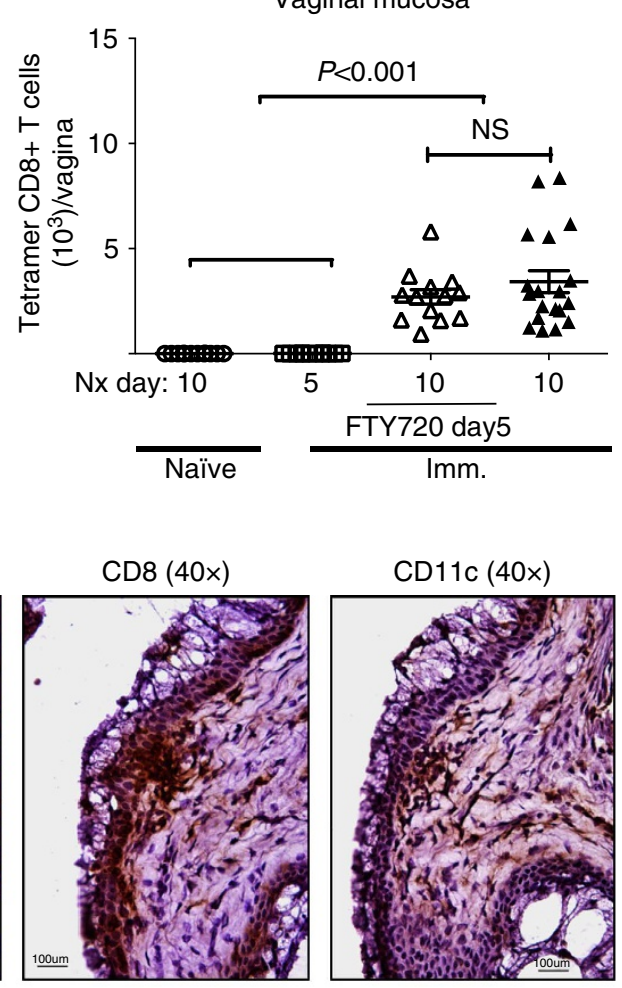

$\operatorname{CD11c}(40 x)$
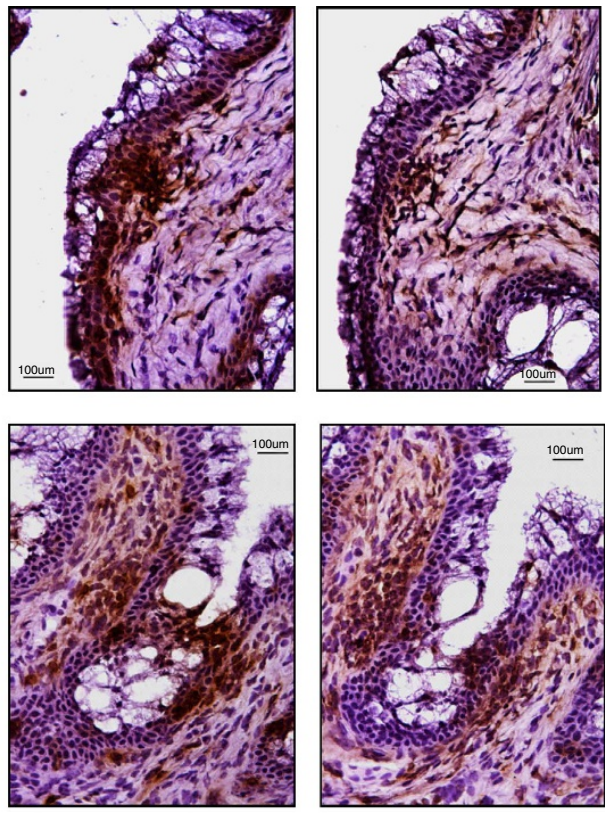

Figure 7 | Local formation of Ag-specific IVALT in the vaginal mucosa of Ivag-immunized WT mice. (a-c) The absolute number of Ag-specific CD8 ${ }^{+} \mathrm{T}$ cells in blood and vaginal mucosa of naïve and immunized mice either with or without FTY720 treatment. $\bigcirc$, naïve mice euthanized at day 10 PI ( $n=12$ ); $\square$, immunized mice euthanized at day $5 \mathrm{PI}(n=12) ; \triangle$, FTY720-treated immunized mice euthanized at day $10 \mathrm{PI}(n=12) ; \boldsymbol{\Lambda}$, immunized mice euthanized at day $10 \mathrm{PI}(n=18)$. This is the pool of three independently repeated experiments with the same results. (a) The experimental design. (b) The absolute

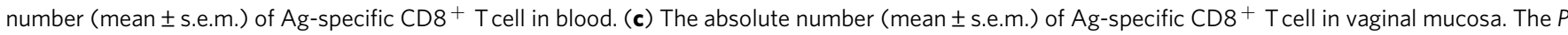
values were generated using one-way analysis of variance plus Tukey's multiple comparison. (d) Representative IHC staining showing the formation of immune cell clusters containing $\mathrm{CD}^{+}, \mathrm{CD}^{+}$and $\mathrm{CD}_{11}{ }^{+}$cells in immunized mice either with or without FTY720 treatment. Scale bar: $100 \mu \mathrm{m}$ in $\times 40$ photomicrographs; $400 \mu \mathrm{m}$ in $\times 10$ photomicrographs. Imm., immunized.

immunized mice (Fig. 7c). To determine whether the rAd5-gp140 Ivag immunization could induce the formation of IVALT similar to that seen in rAd5-SIINFEKL immunized animals (Fig. 1d), we examined vaginal tissue sections of immunized mice either with or without FTY720 treatment by IHC (Fig. 7d). The formation of IVALT containing $\mathrm{CD}^{+}, \mathrm{CD}^{+}$and $\mathrm{CD} 11 \mathrm{c}^{+}$cells was observed in the immunized animals either treated or untreated with FTY720. Because the FTY720 treatment diminished the number of Ag-specific CD8 ${ }^{+} \mathrm{T}$ cells to a background level in the bloodstream (Fig. 7b), which is the only pathway through which the primed $\mathrm{T}$ cells can enter the vaginal mucosa from other tissue compartments, we concluded that the quantity of vaginal Agspecific immune $\mathrm{CD}^{+}{ }^{+} \mathrm{T}$ cells as well as the capability of IVALT formation did not depend on blood replenishment.

To identify the proliferating Ag-specific $\mathrm{CD} 8{ }^{+} \mathrm{T}$ cells within the vaginal mucosa, we treated the immunized mice from day 5-9 with bromodeoxyuridine (BrdU), a synthetic thymidine analogue that can be incorporated into newly synthesized DNA during cell 
a

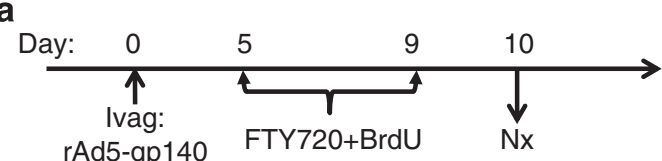

b

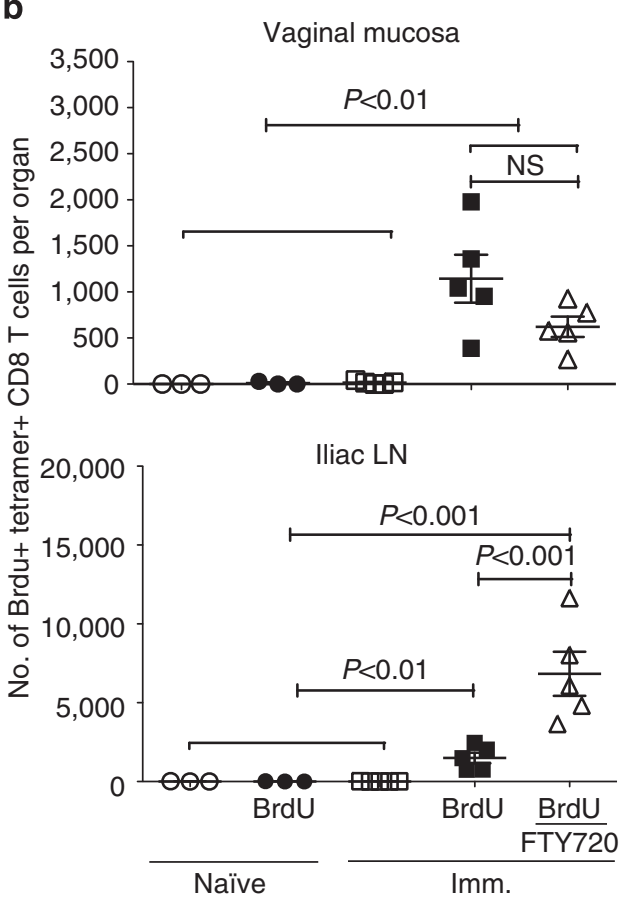

Figure 8 | The local proliferation of endogenous Ag-specific CD8 ${ }^{+}$ T cells in the vaginal mucosa of Ivag-immunized WT mice with or without FTY720 treatment. The $\mathrm{BrdU}^{+} \mathrm{Ag}$-specific $\mathrm{CD} 8{ }^{+} \mathrm{T}$ cells in vaginal mucosa of FTY720-treated or -untreated immunized mice. $\bigcirc$, naïve mice $(n=3) ; \bullet$, BrdU-treated naïve mice $(n=3) ; \square$, immunized mice $(n=5)$;

口, BrdU-treated immunized mice $(n=5) ; \triangle$, FTY720 and BrdU-treated immunized mice $(n=5)$. This is representative of two independently repeated experiments with the same results. (a) The experimental design. (b) The absolute number (mean \pm s.e.m.) of $\mathrm{BrdU}^{+} \mathrm{Ag}$-specific CD8 $^{+}$ $T$ cells in vaginal mucosa and iliac $L N s$. The $P$ values were generated using a one-way analysis of variance plus Tukey's multiple comparisons. Imm., immunized.

proliferation (Fig. 8a). At day $10 \mathrm{PI}$, the amount of $\mathrm{BrdU}^{+} \mathrm{Ag}^{-}$ specific $\mathrm{CD} 8{ }^{+} \mathrm{T}$ cells in the vaginal mucosa was similar in both FTY720-treated and -untreated immunized groups (Fig. 8b), independent of trafficking from LNs. In contrast, the FTY720 treatment caused a significant increase of $\mathrm{BrdU}^{+} \mathrm{Ag}$-specific $\mathrm{CD}^{+} \mathrm{T}$ cells in the iliac LNs due to blockage of T-cell egress from DLNs (Fig. 8b). Thus, similar to what is found in the lung ${ }^{41}$, the type-II vaginal mucosa can support $\mathrm{Ag}$-specific $\mathrm{CD} 8^{+} \mathrm{T}$-cell local expansion that largely contributed to the quantity (the absolute number of Ag-specific $\mathrm{CD} 8^{+} \mathrm{T}$ cells) and the quality (the formation of IVALT) of vaginal Ag-specific $\mathrm{CD}^{+}$ $\mathrm{T}$ immunity, independent of systemic T-cell recruitment.

\section{Discussion}

In the present study, our results demonstrated for the first time that the vaginal mucosa can support the Ag-specific immune priming of naïve $\mathrm{T}$ cells and promote Ag-specific T-cell local expansion, despite the absence of MALT or secondary lymphoid tissues. Therefore, in addition to the known role of DLNs, the type-II vaginal mucosa can also act as an inductive site for the generation of primary CD8 ${ }^{+}$T-cell mucosal immune responses independent of the DLNs, contrary to accepted belief.

The priming of immune responses in type-II mucosa is thought to occur only in secondary lymphoid tissues, such as DLNs where the APC-primed naïve T cells can become memory $\mathrm{T}$ cells and traffic back to the mucosal sites. However, in direct contrast to this existing widely believed paradigm, we have shown vaginal $\mathrm{Ag}$-specific $\mathrm{CD} 8{ }^{+} \mathrm{T}$-cell immune responses are possible following primary Ivag vaccination in mice lacking DLNs (Fig. 1). In agreement with our finding is a recent study by Roth et al. ${ }^{13}$ who reported the induction of HSV-specific immune responses in the vagina of $\mathrm{LN}$-deficient $\mathrm{LT} \alpha \mathrm{KO}$ mice. Further, the priming of $\mathrm{CD}^{+}{ }^{+} \mathrm{T}$ cells in the absence of $\mathrm{LN}$ involvement has been reported in the lungs (in type I mucosa) ${ }^{1-3}$ and other nonlymphoid organs, such as the liver ${ }^{30,31}$. Indeed, in our study, we also show the induction of $\mathrm{CD} 8{ }^{+} \mathrm{T}$-cell priming in the liver (Fig. 3g,h). Moyron-Quiroz et al. ${ }^{1,2}$ showed that the induction of $\mathrm{CD}^{+}{ }^{+} \mathrm{T}$ cells in the lungs without $\mathrm{LN}$ involvement may occur in induced bronchial-associated lymphoid tissues in type I mucosa. Likewise, in this study, we demonstrate by IHC the formation of IVALT in the vaginal mucosa following primary IVag vaccination. Similar induction of IVALT has been reported in hormone treated, $\mathrm{TK}^{-} \mathrm{HSV}$-vaccinated mice that are challenged with WT HSV ${ }^{15}$. Despite previous studies showing immune protection in the mice without $\mathrm{LNs}^{1-3,13}$ and the presence of IVALT $^{15}$, none of those studies were able to definitively demonstrate the primary immune inductive site because they did not exclude the possibilities that the immune priming can occur in other non-lymphoid organs, such as liver and traffic to the vagina. By using the dual-transfer model to exclude trafficking from these or any other sites through the bloodstream, we have now been able to definitively demonstrate that the vaginal type-II mucosa acts as an inductive site for primary $\mathrm{CD} 8^{+}$T-cell immunity. Therefore, our results demonstrated a new paradigm of IVALT-associated local primary immune induction in type-II mucosa (that lacks structured lymphoid tissues), which is totally independent of any structured lymphoid and/or even nonlymphoid tissues outside vaginal mucosa.

These results also demonstrate the ability to induce local vaginal immunity more rapidly than could occur if time were required for DCs to carry Ag to the DLNs and then for T cells to migrate back through the blood to the mucosa. As we have seen in the dual-transfer studies, the latter pathway requires additional time (Fig. 3e versus Fig. 4d). This was confirmed in the kinetic study in unmanipulated mice (Fig. 5a,b). This kinetic difference has important implications for vaccine delivery strategies aimed at acute protective immunity.

Since the number of endogenous naïve $\mathrm{T}$ cells specific to any one peptide-major histocompatibility complex complex is extremely small (20-200 per mouse) ${ }^{42}$, it is almost impossible to detect a reliable population of Ag-specific $\mathrm{T}$ cells before clonal expansion, after which the Ag-specific $\mathrm{T}$ cells are not naïve anymore. To test our hypothesis, we characterized vaginal local immune priming of naive $\mathrm{CD} 8{ }^{+} \mathrm{T}$ cells by the Ag-specific activation of CD44-depleted $\mathrm{Rag}^{-1-} \mathrm{OT}-1 \mathrm{CD}^{+}{ }^{+} \mathrm{T}^{-1} \mathrm{cell}^{43}$ isolated from the spleen of naïve animals (Fig. 3a), because OT-1 or similar TCR transgenic $\mathrm{T}$ cells are the only source of naïve $\mathrm{CD}^{+} \mathrm{T}$ cells of a homogeneous Ag specificity. The adoptively transferred OT-1 CD8 ${ }^{+}$cells have been widely used and accepted as naïve Ag-specific $\mathrm{T}$ cells by many experienced labs, in which the investigators published their studies using the transferred cells from unimmunized transgenic mice as naïve ${ }^{44-53}$, often even without further purification for CD62 $\mathrm{L}^{\text {high }}$ and $\mathrm{CD} 44^{\text {low }}$ cells. In the current study, we depleted all the CD62 $\mathrm{L}^{\text {low }}$ and CD44high cells right before the adoptive transfer and brought the purity of our transferred naïve CD8 ${ }^{+} \mathrm{T}$ cells up to $98.5 \%$ (Fig. 3a). Using 
the dual-transfer model providing a large amount of naïve $\mathrm{T}$ cells at the local site, we could detect early immune priming at $24 \mathrm{~h} \mathrm{PI}$, which is too short for the primed endogenous naïve $\mathrm{T}$ cell to reach a detectable level, most likely through clonal expansion. The rapid detection of response by TCR transgenic $\mathrm{T}$ cells due to the greater numbers of Ag-specific cells without an expansion phase is therefore critical to carry out such studies, but does not bear on their naïve status.

We, like many other investigators studying vaginal mucosal immunology $12,13,15,21,22,26,54$, treated all the experimental animals with Depo-Provera, a long-acting progesterone, because vaginal Agspecific CD8 ${ }^{+}$T-cell immunity could not be consistently induced in animals without Depo-Provera treatment. In contrast to humans, the mouse passes through 4 oestrous stages during an oestrous cycle that lasts only 4 days and then repeats: proestrus, oestrus, metestrus and dioestrus ${ }^{55}$. Among the 4 stages, more $\mathrm{CD} 8{ }^{+} \mathrm{T}$ cells have been found present in vaginal mucosa during dioestrus ${ }^{56}$. Although the detailed mechanisms of Depo-provera effects on vaginal mucosal immunity remain to be clearly determined, the use of Depo-provera, the dominant hormone in dioestrus, has been shown to affect the thickness of vaginal epithelium ${ }^{22}$, the forming of IVALT ${ }^{15,54}$ and the accumulation of CD11c ${ }^{+}$cells $^{22}$. We think the use of Depoprovera, through the regulation of multiple immune parameters, may make the vaginal mucosa more suitable to our Ivag immunization. Without such synchronization of mice that otherwise undergo rapid cyclic changes, it is impossible to carry out controlled studies of vaginal immunity.

It is well accepted that $\mathrm{T}$-cell-mediated local protective immunity can play an important role to control the viral infection in peripheral tissue compartments ${ }^{11,24-26}$. In addition to the cytotoxic effects based on direct cell-to-cell contact, the tissueresident $\mathrm{T}$ memory cells $\left(\mathrm{T}_{\mathrm{RM}}\right)$ have been recently found to undergo local development in skin ${ }^{57}$ and possess more protective immune functions including the triggering of tissue-wide innate and adaptive immune responses ${ }^{58,59}$. Therefore, a goal should be a more efficient vaccine strategy, which can generate strong local T-cell-mediated immune responses ${ }^{60}$ without widespread systemic immune activation that facilitates the replication of some viruses, such as HIV and SIV ${ }^{61,62}$. Because the DLNs are not required to induce vaginal immunity, it may be possible to induce local immunity without systemic immune activation.

Our study outlines definitive evidence for the induction of primary immune induction in vaginal type-II mucosa, thereby identifying a new pathway of vaccine-induced mucosal immunity and a new rationale for the design of future mucosal vaccine strategies.

\section{Methods}

Mice. Because this was a study of vaginal immunity, all mice used in the current study were females from $16-20$ weeks of age. $B A L B / c$ and $C 57 B L / 6$ mice were purchased from NCI animal facility (Frederick, MD). OT-1, LT $\alpha$ KO and CXCR5 $\mathrm{KO}$ mice (all with $C 57 B L / 6$ background) were purchased from Jackson Laboratories (Bar Harbor, ME). All experimental protocols were approved by and carried out under the guidelines of the NCI's Animal Care and Use Committee. All the animals were grouped randomly and the number of animals in each group is equal to or greater than $3(n \geq 3)$. All the experiments were repeated at least two (two to four) times.

Reagents and inocula. Replication-deficient adenovirus 5-expressing HIVgp140 (rAd5-gp140) was developed and kindly provided by Dr Gary Nabel (Vaccine Research Center, NIAID, Bethesda MD). Replication-deficient adenovirus 5expressing SIINFEKL (rAd5-SIINFEKL) was first developed by Dr S.E. Hensley in Jon Yewdell's and Jack Bennink's laboratory (NIAID) and kindly provided by Dr Robert Seder in (NIAID). The FTY720 was purchased from Cayman Chemical (Ann Arbor, MI). The SIINFEKL peptide was purchased from Polypeptide Laboratory (San Diego, CA). The mutant E. coli labile toxin (mLT) was a kind gift of Dr John Clements (Tulane University, New Orleans). The DOTAP and BrdU were purchased from Sigma (St Louis, MO). The Depo-provera was purchased from the Department of Veterinary Medicine, NIH.
Intravascular T-cell staining. Alexa fluor-647 labelled anti-mouse Thy1.2 antibody was diluted in PBS at $250 \mathrm{ng} \mathrm{ml}^{-1}$. Each mouse was injected with $100 \mu \mathrm{l}$ of diluted antibody through the tail vein. All the animals were euthanized at $1 \mathrm{~min}$ post i.v. injection, a time point at which all the blood $\mathrm{T}$ cells in retro-orbital sinus were Thy1.2 positive.

Dual transfer. The CD8 ${ }^{+} \mathrm{T}$ cells were isolated from $\mathrm{Rag}^{-1-} \mathrm{OT}-1 \mathrm{TCR}$ transgenic mice using a CD8 isolation kit (Miltenyi Biotec, Auburn, CA). The CD $44^{+}$cells were depleted using biotinylated anti-mouse CD44 (1:2,000 dilution, BioLegend, San Diego, CA) and anti-biotin beads (Miltenyi Biotec). The naïve CD8 ${ }^{+}$OT-1 T cells were labelled with either CFSE or violet dye (both from Invitrogen, Grand Island, NY) at $5 \mu \mathrm{M}$. Ten microlitres of CFSE-labelled cells $\left(1 \times 10^{8} \mathrm{ml}^{-1}\right)$ were directly injected into the vaginal tissue (Ivag) using a Hamilton syringe with a $32 \mathrm{G}$ needle. One hundred microlitres of violet dye-labelled cells $\left(1 \times 10^{7} \mathrm{ml}^{-1}\right)$ was injected into the tail vein (i.v.). The mice were under isoflurane general anaesthesia during the performance of dual transfer.

Immunization. All the immunizations in this study were performed Ivag. The dose of each inoculum was: $2 \times 10^{7}$ p.f.u. of rAd5-gp140, $1 \times 10^{7}$ of rAd5-SIINFEKL or $40 \mu \mathrm{g}$ of SIINFEKL peptide plus $5 \mu \mathrm{g}$ of mutant E. coli labile toxin (mLT) and equal volume of DOTAP. Ivag immunizations were performed using a $20-\mu$ l pipette tip to apply the inoculum into the vaginal canal atraumatically. All the immunized mice were maintained under inhalation anaesthesia for $20 \mathrm{~min}$.

Vaginal tissue culture. The resected vaginal tissue was digested in RPMI 1640 medium (GIBCO, Grand Island, NY) containing collagenase-D (400 $\mathrm{U} \mathrm{ml}^{-1}$, Roche Indianapolis, IN), DNase-I (2.5 mg ml ${ }^{-1}$, Roch), Penicillin-Streptomycin $\left(100 \mu \mathrm{g} \mathrm{ml}^{-1}\right.$, GIBCO), HEPES buffer $(20 \mathrm{mM}$, GIBCO) and fetal bovine serum $(10 \%$, GIBCO). The digestion lasted for $20 \mathrm{~min}$ with stirring. The vaginal tissue was then smashed through a $70-\mu \mathrm{m}$ cell strainer (Fisher, Pittsburgh, PA) followed by CD8 depletion using Dynal Beads (Life Technologies). The CD8-depleted vaginal tissue, either with or without CD11c-depletion (CD11c kit, Miltenyi Biotec), was co-cultured with $1 \times 10^{6} \mathrm{CFSE}$ (Invitrogen)-labelled naïve OT-1 CD8 ${ }^{+} \mathrm{T}$ cells in RPMI medium containing Penicillin-Streptomycin $\left(100 \mu \mathrm{g} \mathrm{ml}^{-1}\right.$, GIBCO), HEPES buffer ( $10 \mathrm{mM}$, GIBCO), L-glutamine ( $2 \mathrm{mM}$, GIBCO), gentamicin $\left(50 \mathrm{mg} \mathrm{ml}^{-1}\right.$, Sigma), MEM non-essential amino acid (GIBCO), sodium pyruvate (1 mM, GIBCO), 2-mercaptoethanol $\left(10 \mu \mathrm{M}\right.$, Sigma), fungizone $\left(2.5 \mu \mathrm{g} \mathrm{ml}^{-1}\right.$, GIBCO) and fetal bovine serum (20\%, GIBCO).

Antibodies and flow cytometry. Anti-mouse CD3, CD8, CD69, CD44, CD25 and CD62L were purchased from Biolegend and used to stain the cells at the concentration of $150 \mathrm{ng} \mathrm{ml}^{-1}$. Data were collected using a LSRII using DIVA software (BD Biosciences, San Jose, CA) or a FACSCalibur flow cytometer using CellQuest software (BD Biosciences). The analysis of data was performed using FlowJo (Tree Star, Ashland, OR).

Depo-Provera synchronization. All the mice in our study received Depo-Provera at a dose of $3 \mathrm{mg}$ per mouse through subcutaneous injection 5 days before each experiment.

FTY720 treatments. FTY720 was given by IP injection at an initial dose of $50 \mu \mathrm{g}$ per mouse followed by daily maintenance injection at a dose of $5 \mu \mathrm{g}$ per mouse.

Bromodeoxyuridine (BrdU) treatment and staining. The BrdU (1 mg per mouse, Sigma) was given by daily intraperitoneal injections for 5 days. The staining of BrdU-positive cells was performed using a Brdu staining kit (BD Biosciences) according to the manufacturer's instructions.

Immunohistochemistry. The vagina was embedded in optimal cutting temperature compound (O.C.T.) and snap frozen in liquid nitrogen precooled isopentane. Frozen vaginal tissue blocks were cut into sections with a thickness of $5 \mu \mathrm{m}$, stored in $-70^{\circ} \mathrm{C}$ until use. Cryostat sections were fixed in acetone for $5 \mathrm{~min}$, rehydrated in PBS and incubated overnight with primary antibodies including rabbit antimouse CD3 (1:100 dilution, AbCam), rat anti-mouse CD8 (1:200 dilution, Biolegend) and hamster anti-mouse CD11c (1:150 dilution, Biolegend). The primary antibodies were washed out three times by PBS followed by the addition of HRPconjugated secondary antibodies (Vector Lab) including horse anti-rabbit IgG, goat anti-rat IgG and goat anti-hamster IgG. The secondary antibodies were incubated in room temperature for $30 \mathrm{~min}$ followed by DAB (kit from Vector Lab) development and hematoxylin (BBC Biochemical) counter staining.

Statistics. The statistics of this study was performed using Prism software. Oneway analysis of variance plus Tukey's multiple comparison was used to compare multiple groups; Student's $t$-test was used to compare two groups. 


\section{References}

1. Moyron-Quiroz, J. E. et al. Role of inducible bronchus associated lymphoid tissue (iBALT) in respiratory immunity. Nat. Med. 10, 927-934 (2004).

2. Moyron-Quiroz, J. E. et al. Persistence and responsiveness of immunologic memory in the absence of secondary lymphoid organs. Immunity 25, 643-654 (2006).

3. Lund, F. E. et al. Lymphotoxin-alpha-deficient mice make delayed, but effective, $\mathrm{T}$ and $\mathrm{B}$ cell responses to influenza. J. Immunol. 169, 5236-5243 (2002)

4. Iqbal, S. M. et al. Elevated T cell counts and RANTES expression in the genital mucosa of HIV-1-resistant Kenyan commercial sex workers. J. Infect. Dis. 192, 728-738 (2005).

5. Kaul, R. et al. HIV-1-specific mucosal CD8 + lymphocyte responses in the cervix of HIV-1-resistant prostitutes in Nairobi. J. Immunol. 164, 1602-1611 (2000).

6. Ferre, A. L. et al. Mucosal immune responses to HIV-1 in elite controllers: a potential correlate of immune control. Blood 113, 3978-3989 (2009).

7. Critchfield, J. W. et al. Magnitude and complexity of rectal mucosa HIV-1specific CD8 + T-cell responses during chronic infection reflect clinical status. PLoS ONE 3, e3577 (2008).

8. Ferre, A. L. et al. HIV controllers with HLA-DRB1 ${ }^{\star} 13$ and HLA-DQB1 ${ }^{\star} 06$ alleles have strong, polyfunctional mucosal CD4 + T-cell responses. J. Virol. 84, 11020-11029 (2010)

9. Genesca, M. et al. With minimal systemic T-cell expansion, CD8 + T Cells mediate protection of rhesus macaques immunized with attenuated simianhuman immunodeficiency virus SHIV89.6 from vaginal challenge with simian immunodeficiency virus. J. Virol. 82, 11181-11196 (2008).

10. Genesca, M. et al. Protective attenuated lentivirus immunization induces SIVspecific $\mathrm{T}$ cells in the genital tract of rhesus monkeys. Mucosal Immunol. 1, 219-228 (2008)

11. Hansen, S. G. et al. Profound early control of highly pathogenic SIV by an effector memory T-cell vaccine. Nature 473, 523-527 (2011).

12. Shin, H. \& Iwasaki, A. A vaccine strategy that protects against genital herpes by establishing local memory T cells. Nature 491, 463-467 (2012).

13. Roth, K. L. et al. Delayed but effective induction of mucosal memory immune responses against genital HSV-2 in the absence of secondary lymphoid organs. Mucosal Immunol. 6, 56-68 (2012).

14. Tang, V. A. \& Rosenthal, K. L. Intravaginal infection with herpes simplex virus type-2 (HSV-2) generates a functional effector memory $\mathrm{T}$ cell population that persists in the murine genital tract. J. Reprod. Immunol. 87, 39-44 (2010).

15. Gillgrass, A. E., Tang, V. A., Towarnicki, K. M., Rosenthal, K. L. \& Kaushic, C. Protection against genital herpes infection in mice immunized under different hormonal conditions correlates with induction of vagina-associated lymphoid tissue. J. Virol. 79, 3117-3126 (2005).

16. Iwasaki, A. Antiviral immune responses in the genital tract: clues for vaccines. Nat. Rev. Immunol. 10, 699-711 (2010).

17. Neutra, M. R. \& Kozlowski, P. A. Mucosal vaccines: the promise and the challenge. Nat. Rev. Immunol. 6, 148-158 (2006).

18. Pavot, V., Rochereau, N., Genin, C., Verrier, B. \& Paul, S. New insights in mucosal vaccine development. Vaccine 30, 142-154 (2012).

19. Woodrow, K. A., Bennett, K. M. \& Lo, D. D. Mucosal vaccine design and delivery. Annu. Rev. Biomed. Eng. 14, 17-46 (2012).

20. Lee, H. K. et al. Differential roles of migratory and resident DCs in T cell priming after mucosal or skin HSV-1 infection. J. Exp. Med. 206, 359-370 (2009).

21. Nakanishi, Y., Lu, B., Gerard, C. \& Iwasaki, A. CD8 (+) T lymphocyte mobilization to virus-infected tissue requires CD4 $(+)$ T-cell help. Nature 462, 510-513 (2009)

22. Zhao, X. et al. Vaginal submucosal dendritic cells, but not Langerhans cells, induce protective Th1 responses to herpes simplex virus-2. J. Exp. Med. 197, 153-162 (2003)

23. Sheridan, B. S. \& Lefrancois, L. Regional and mucosal memory T cells. Nat. Immunol. 12, 485-491 (2011).

24. Jiang, X. et al. Skin infection generates non-migratory memory CD8 $+\mathrm{T}(\mathrm{RM})$ cells providing global skin immunity. Nature 483, 227-231 (2012).

25. Mackay, L. K. et al. Long-lived epithelial immunity by tissue-resident memory T (TRM) cells in the absence of persisting local antigen presentation. Proc. Natl Acad. Sci. USA 109, 7037-7042 (2012).

26. Gebhardt, T. et al. Memory T cells in nonlymphoid tissue that provide enhanced local immunity during infection with herpes simplex virus. Nat. Immunol. 10, 524-530 (2009).

27. De Togni, P. et al. Abnormal development of peripheral lymphoid organs in mice deficient in lymphotoxin. Science 264, 703-707 (1994).

28. Alimzhanov, M. B. et al. Abnormal development of secondary lymphoid tissues in lymphotoxin beta-deficient mice. Proc. Natl Acad. Sci. USA 94, 9302-9307 (1997).

29. Crispe, I. N. The liver as a lymphoid organ. Annu. Rev. Immunol. 27, 147-163 (2009).
30. Bertolino, P., Bowen, D. G., McCaughan, G. W. \& Fazekas de St Groth, B. Antigen-specific primary activation of CD8 $+\mathrm{T}$ cells within the liver. J. Immunol. 166, 5430-5438 (2001).

31. Bottcher, J. P. et al. Liver-primed memory T cells generated under noninflammatory conditions provide anti-infectious immunity. Cell Rep. 3, 779-795 (2013)

32. Galkina, E. et al. Preferential migration of effector CD8 $+\mathrm{T}$ cells into the interstitium of the normal lung. J. Clin. Invest. 115, 3473-3483 (2005).

33. Matloubian, M. et al. Lymphocyte egress from thymus and peripheral lymphoid organs is dependent on S1P receptor 1. Nature 427, 355-360 (2004).

34. Mackay, C. R., Marston, W. L. \& Dudler, L. Naive and memory T cells show distinct pathways of lymphocyte recirculation. J. Exp. Med. 171, 801-817 (1990).

35. Butcher, E. C. \& Picker, L. J. Lymphocyte homing and homeostasis. Science 272, 60-66 (1996).

36. Hofmann, M., Brinkmann, V. \& Zerwes, H. G. FTY720 preferentially depletes naive $\mathrm{T}$ cells from peripheral and lymphoid organs. Int. Immunopharmacol. 6, 1902-1910 (2006).

37. Staton, T. L. et al. CD8 + recent thymic emigrants home to and efficiently repopulate the small intestine epithelium. Nat. Immunol. 7, 482-488 (2006).

38. Inman, C. F., Murray, T. Z., Bailey, M. \& Cose, S. Most B cells in non-lymphoid tissues are naive. Immunol. Cell Biol. 90, 235-242 (2012).

39. Cose, S., Brammer, C., Khanna, K. M., Masopust, D. \& Lefrancois, L. Evidence that a significant number of naive $\mathrm{T}$ cells enter non-lymphoid organs as part of a normal migratory pathway. Eur. J. Immunol. 36, 1423-1433 (2006).

40. Ansel, K. M. et al. A chemokine-driven positive feedback loop organizes lymphoid follicles. Nature 406, 309-314 (2000).

41. McGill, J. \& Legge, K. L. Cutting edge: contribution of lung-resident T cell proliferation to the overall magnitude of the antigen-specific CD8 T cell response in the lungs following murine influenza virus infection. J. Immunol. 183, 4177-4181 (2009).

42. Moon, J. J. et al. Naive CD4(+) T cell frequency varies for different epitopes and predicts repertoire diversity and response magnitude. Immunity 27, 203213 (2007).

43. Goldrath, A. W., Bogatzki, L. Y. \& Bevan, M. J. Naive T cells transiently acquire a memory-like phenotype during homeostasis-driven proliferation. J. Exp. Med. 192, 557-564 (2000)

44. Castellino, F. et al. Chemokines enhance immunity by guiding naive CD8 + $\mathrm{T}$ cells to sites of CD4 $+\mathrm{T}$ cell-dendritic cell interaction. Nature 440, 890-895 (2006).

45. Mouries, J. et al. Plasmacytoid dendritic cells efficiently cross-prime naive T cells in vivo after TLR activation. Blood 112, 3713-3722 (2008).

46. Pape, K. A. et al. Use of adoptive transfer of T-cell-antigen-receptor-transgenic $\mathrm{T}$ cell for the study of T-cell activation in vivo. Immunol. Rev. 156, 67-78 (1997).

47. Ciabattini, A., Pettini, E., Andersen, P., Pozzi, G. \& Medaglini, D. Primary activation of antigen-specific naive CD4 + and CD8 $+\mathrm{T}$ cells following intranasal vaccination with recombinant bacteria. Infect. Immun. 76, 5817 5825 (2008).

48. Luci, C. et al. Dendritic cell-mediated induction of mucosal cytotoxic responses following intravaginal immunization with the nontoxic B subunit of cholera toxin. J. Immunol. 176, 2749-2757 (2006).

49. Rechtsteiner, G., Warger, T., Osterloh, P., Schild, H. \& Radsak, M. P. Cutting edge: priming of CTL by transcutaneous peptide immunization with imiquimod. J. Immunol. 174, 2476-2480 (2005).

50. Kieper, W. C. \& Jameson, S. C. Homeostatic expansion and phenotypic conversion of naive T cells in response to self peptide/MHC ligands. Proc. Natl Acad. Sci. USA 96, 13306-13311 (1999).

51. Schenkel, J. M. et al. Resident memory CD8 T cells trigger protective innate and adaptive immune responses. Science 346, 98-101 (2014).

52. Plumlee, C. R., Sheridan, B. S., Cicek, B. B. \& Lefrancois, L. Environmental cues dictate the fate of individual CD8 $+\mathrm{T}$ cells responding to infection. Immunity 39, 347-356 (2013)

53. Mehlhop-Williams, E. R. \& Bevan, M. J. Memory CD $8+$ T cells exhibit increased antigen threshold requirements for recall proliferation. J. Exp. Med. 211, 345-356 (2014)

54. Cuburu, N. et al. Intravaginal immunization with HPV vectors induces tissueresident CD8 + T cell responses. J. Clin. Invest. 122, 4606-4620 (2012).

55. Coleman, D. L. Biology of The Laboratory Mouse (McGraw-Hill Book Company, 1966)

56. Parr, M. B. \& Parr, E. L. Langerhans cells and T lymphocyte subsets in the murine vagina and cervix. Biol. Reprod. 44, 491-498 (1991).

57. Mackay, L. K. et al. The developmental pathway for CD103 $(+) \mathrm{CD} 8+$ tissueresident memory T cells of skin. Nat. Immunol. 14, 1294-1301 (2013).

58. Schenkel, J. M. et al. T cell memory. Resident memory CD8 T cells trigger protective innate and adaptive immune responses. Science 346, 98-101 (2014)

59. Ariotti, S. et al. T cell memory. Skin-resident memory CD8 $(+) \mathrm{T}$ cells trigger a state of tissue-wide pathogen alert. Science 346, 101-105 (2014). 
60. Belyakov, I. M. et al. Mucosal AIDS vaccine reduces disease and viral load in gut reservoir and blood after mucosal infection of macaques. Nat. Med. 7, 1320-1326 (2001).

61. Brenchley, J. M. et al. Microbial translocation is a cause of systemic immune activation in chronic HIV infection. Nat. Med. 12, 1365-1371 (2006).

62. Estes, J. D. et al. Damaged intestinal epithelial integrity linked to microbial translocation in pathogenic simian immunodeficiency virus infections. PLoS Pathog. 6, e1001052 (2010).

63. Turgeon, M. L. Clinical Hematology Theory and Procedures 4th edn, Vol. 1 (Lippincott Williams \& Wilkins, 2005).

\section{Acknowledgements}

This work is supported by NCI intramural funding ZO1 SC 004020. We thank Drs Warren Strober and Brian Kelsall for the critical reading of this manuscript, Dr Leonid Margolis' lab for valuable suggestions on vaginal tissue culture, Dr Shunsuke Sakai and Dr Daniel L. Barber for the advice on intravascular T-cell staining, the NIH tetramer facility for providing tetramer reagents, Dr Laurel Lagenaur and NIAID Biological Imaging Facility for photomicrography of the IHC stained vaginal tissue sections.

\section{Author contributions}

Y.W., Y.S. and J.A.B. studied the concept and design; J.C.S. and J.C.M. were responsible for Adenovirus preparation; Y.W., A.E.H. and S.K. were responsible for conducting the experiments and the acquisition of data; Y.W., Y.S. and J.A.B. analysed and interpreted the data. All authors contributed to writing and editing of the manuscript.

\section{Additional information}

Supplementary Information accompanies this paper at http://www.nature.com/ naturecommunications

Competing financial interests: The authors declare no competing financial interests.

Reprints and permission information is available online at http://npg.nature.com/ reprintsandpermissions/

How to cite this article: Wang, Y. et al. Vaginal type-II mucosa is an inductive site for primary CD8 ${ }^{+}$T-cell mucosal immunity. Nat. Commun. 6:6100 doi: $10.1038 /$ ncomms7100 (2015). 